\title{
Nanoengineering Hybrid Supramolecular Multilayered Biomaterials Using Polysaccharides and Self-Assembling Peptide Amphiphiles
}

\author{
João Borges, * Maria P. Sousa, Goksu Cinar, Sofia G. Caridade, Mustafa O. Guler, \\ and João F. Mano*
}

Developing complex supramolecular biomaterials through highly dynamic and reversible noncovalent interactions has attracted great attention from the scientific community aiming key biomedical and biotechnological applications, including tissue engineering, regenerative medicine, or drug delivery. In this study, the authors report the fabrication of hybrid supramolecular multilayered biomaterials, comprising high-molecular-weight biopolymers and oppositely charged low-molecular-weight peptide amphiphiles (PAs), through combination of self-assembly and electrostatically driven layer-bylayer (LbL) assembly approach. Alginate, an anionic polysaccharide, is used to trigger the self-assembling capability of positively charged PA and formation of ID nanofiber networks. The LbL technology is further used to fabricate supramolecular multilayered biomaterials by repeating the alternate deposition of both molecules. The fabrication process is monitored by quartz crystal microbalance, revealing that both materials can be successfully combined to conceive stable supramolecular systems. The morphological properties of the systems are studied by advanced microscopy techniques, revealing the nanostructured dimensions and 1D nanofibrous network of the assembly formed by the two molecules. Enhanced $\mathrm{C} 2 \mathrm{C} 12$ cell adhesion, proliferation, and differentiation are observed on nanostructures having PA as outermost layer. Such supramolecular biomaterials demonstrate to be innovative matrices for cell culture and hold great potential to be used in the near future as promising biomimetic supramolecular nanoplatforms for practical applications.

in Chemistry in 1987, there has been a growing interest by the scientific community in this very active and expanding field of chemical research. Inspired by such work, scientists have been focusing on the design and fabrication of robust, complex, self-organized and ordered nano-, micro-, and macrostructured functional supramolecular systems, unfeasible by covalent bonds, to cover multiple applications. ${ }^{[4]}$

Taking biological systems as an unprecedented source of endless inspiration and making use of the most basic concepts of supramolecular chemistry, namely molecular recognition, self-assembly, selfassociation, and self-organization, scientists have been challenged toward the bottom-up fabrication of increasingly complex, yet adaptive and functional supramolecular biomaterials, with outstanding properties, aiming at mimicking natural systems. ${ }^{4 \mathrm{~b}, \mathrm{k}, 5]}$

To date, a great focus has been devoted to the design and development of biologically derived functional supramolecular architectures with the main aim of emulating the complex composition, structure, dynamic, and functional behavior, and hierarchical organization of the native

\section{Introduction}

Since the pioneering work by Pedersen, ${ }^{[1]}$ Cram, ${ }^{[2]}$ and Lehn ${ }^{[3]}$ on supramolecular chemistry, recognized with the Nobel Prize extracellular matrix (ECM). ${ }^{[5 e, 6]}$ Such bioinspired supramolecular systems rely on the spontaneous self-assembly of a set of molecular building blocks (e.g., proteins, polysaccharides, peptides, amino acids, or nucleic acids) through an interplay

\footnotetext{
Dr. J. Borges,,$^{[+]}$M. P. Sousa, ${ }^{[+]}$Dr. S. G. Caridade, ${ }^{[+]}$Prof. J. F. Mano ${ }^{[+]}$ 3B's Research Group - Biomaterials

Biodegradables and Biomimetics

University of Minho

Headquarters of the European Institute of Excellence

on Tissue Engineering and Regenerative Medicine

AvePark - Parque de Ciência e Tecnologia

Zona Industrial da Gandra 4805-017, Barco, Guimarães, Portugal

E-mail: joaoborges@ua.pt; jmano@ua.pt

Dr. J. Borges, M. P. Sousa, Dr. S. G. Caridade, Prof. J. F. Mano

ICVS/3B's - PT Government Associate Laboratory

Braga/Guimarães, Portugal
}

DOI: 10.1002/adfm.201605122

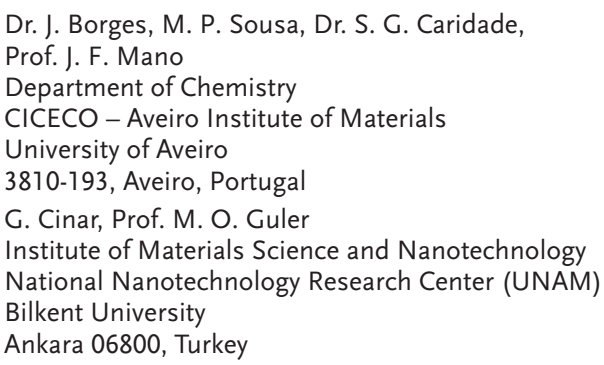

${ }^{[+]}$Present address: Department of Chemistry, CICECO - Aveiro Institute of Materials, University of Aveiro, 3810-193 Aveiro, Portugal 
of highly dynamic noncovalent intermolecular forces. ${ }^{[3,4 b, c, 5 b, c]}$ Indeed, they can incorporate the ECM's key features, including the chemical, mechanical, and topographical cues, thus being of paramount importance for diagnostics, therapy, drug delivery, tissue engineering, and regenerative medicine, or as devices to advance healthcare.

Among the toolbox of self-assembling building blocks, naturally inspired peptides, especially peptide amphiphiles (PAs), have aroused particular interest to make supramolecular ECM-like ensembles of nanostructures due to their easy and cost-effective synthesis, inherent biocompatibility and biodegradability, low toxicity, chemical versatility, easy functionality, self-assembling capability in aqueous medium, and customizable bioactivity. ${ }^{[7]}$ The PAs can easily interact with several biologically active molecules, such as polyelectrolytes or proteins, thus enabling the design of well-defined and hierarchically ordered self-assembled bioinspired supramolecular structures exhibiting multifunctionalities. For instance, the fabrication of hierarchically ordered self-assembled membranes at the interface between two aqueous solutions of oppositely charged molecules, namely positively charged PA and negatively charged biopolymer or protein molecule, has been recently demonstrated. ${ }^{[8]}$ These hierarchical ordered membranes, which have demonstrated a high binding affinity for bioactive molecules, offer a bioinstructive environment for cells to adhere, spread, proliferate, and even differentiate, thus revealing an immeasurable potential for a plethora of biomedical applications. ${ }^{[5 b, 7 c, 8 d, 9]}$ Besides hierarchically structured membranes, other self-assembled supramolecular systems can also be formed making use of strong electrostatic interactions between small PAs and large macromolecules or simply oppositely charged PA molecules. Such self-assembled supramolecular systems include microcapsules $^{[10]}$ and nanofiber scaffolds. ${ }^{[11]}$

Although very promising, most of the developed supramolecular architectures still lack control in thickness, composition, and structure as well as the functional dynamic nature and structural complexity found in the biological systems, which limits many biomedical applications.

We foresee that these hurdles can be surpassed by fabricating robust supramolecular multifunctional systems with precisely controlled structures making use of the simple, inexpensive, yet flexible, environmental friendly, and highly versatile bottom-up layer-by-layer (LbL) assembly approach. ${ }^{[12]}$ This technique consists on the alternate deposition of an unprecedented source of materials with complementary interactions into multilayers. ${ }^{[13]}$ Moreover, it allows the fabrication of robust coatings on simple 2D planar platforms ${ }^{[14]}$ as well as complex $3 \mathrm{D}$ structures ${ }^{[15]}$ with great potential to address a miscellaneous range of emerging applications, including biomedical and biotechnological, ${ }^{[16]}$ optical, ${ }^{[17]}$ electrical, ${ }^{[18]}$ or energy. ${ }^{[19]}$ The integration of the sequential assembly technology with the selfassembly strategy paves the way for engineering more robust, flexible, and stable supramolecular multifunctional nanostructures to accommodate the need for device application. Such supramolecular nanosystems can simultaneously incorporate various biologically active building blocks and functionalities, including the ECM components, and a customized number of layers, thus reinforcing their unique potential to address several biomedical and healthcare applications. Hence, such synergy may provide a great platform to mimic the complexity, dynamic and structural features, and the functional behavior of the native cellular microenvironment, thus helping researchers to extend the supramolecular nanostructures from the research laboratories to practical applications.

In this work, we designed and engineered novel biomimetic hybrid supramolecular functional nanostructures comprising natural origin high-molecular-weight alginate biopolymer (ALG) and oppositely charged low-molecular-weight self-assembling synthetic PA $\left(\mathrm{K}_{3} \mathrm{PA}\right)$, through the combination of self-assembly and electrostatically driven LbL assembly approach. ALG biopolymer has been selected as the anionic polysaccharide due to its proven biocompatibility, low- or even noncytotoxicity, and nonimmunogenic properties. Moreover, it is a widely and readily available polysaccharide extracted from brown seaweed, thus turning it a very appealing biomaterial for biomedical and biotechnological applications. Furthermore, besides the aforementioned advantages of using self-assembling PA molecules, we have chosen the $\mathrm{K}_{3}$ PA material due to its high solubility in aqueous media and positive charge at the working conditions, and possibility to integrate several bioactive domains. To the best of our knowledge, this work is the first one that reports the combined use of self-assembly and LbL assembly technology, as well as PAs and biopolymers to successfully buildup stable hybrid peptide-based supramolecular nanostructured multilayered biomaterials, with unique structural and functional properties, that could recapitulate the functional and structural aspects of the native cellular environment.

The nanofilm buildup was monitored in situ by quartz crystal microbalance with dissipation monitoring (QCM-D), and the morphological and structural properties were examined by advanced microscopy techniques, including atomic force microscopy (AFM), scanning electron microscopy (SEM), and transmission electron microscopy (TEM). Water contact angle (WCA) measurements were performed to infer about the wettability of the supramolecular multilayered assemblies. Moreover, the in vitro biological performance of the new developed hybrid supramolecular multilayered nanostructures was also assessed in order to prove their biocompatibility and, thus, suitability for addressing biomedical applications, supporting in the near future practically oriented research.

\section{Results and Discussion}

\subsection{Design, Preparation, and Characterization of Self-Assembling Peptide Amphiphile and Polysaccharide Molecules}

Figure 1a shows the chemical structure of the self-assembling PA molecule used in this work $\left(\mathrm{K}_{3} \mathrm{PA}\right.$, chemical formula: LaurylVVAGKKK-Am), which consists of three key structural features: an unbranched hydrophobic lauryl tail $\left(-\mathrm{C}_{12} \mathrm{H}_{23} \mathrm{O}-\right)$, a short $\beta$-sheet forming peptide sequence (-VVAG-) capable of forming intermolecular hydrogen bonding and nanofiber networks, and positively charged hydrophilic amino acids (-KKK-) that enhance its solubility in water. The synthesis of the self-assembling $\mathrm{K}_{3} \mathrm{PA}$ molecule was carried out according to the standard Fmoc solid-phase peptide synthesis method. The liquid chromatography-mass spectrometry (LC-MS) result of the synthesized 
(a)
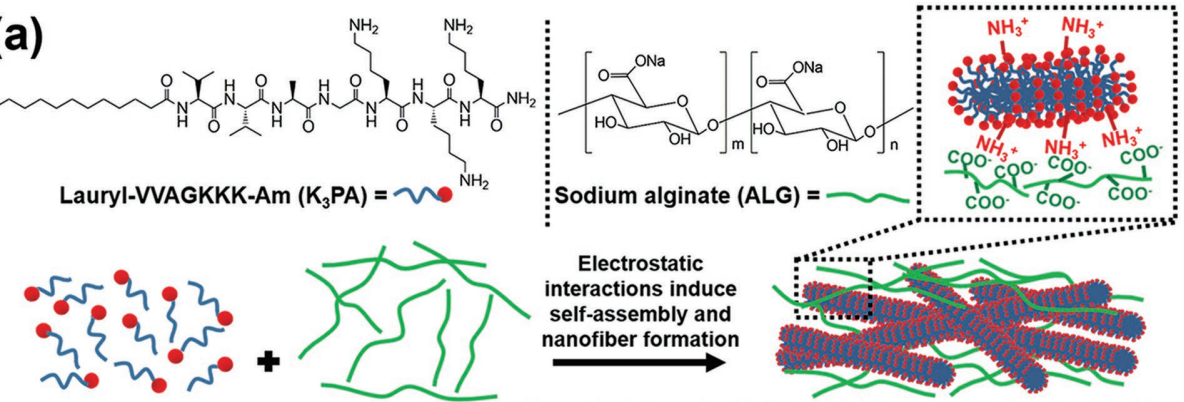

(+) charged $K_{3} P A$

(-) charged ALG

(b)

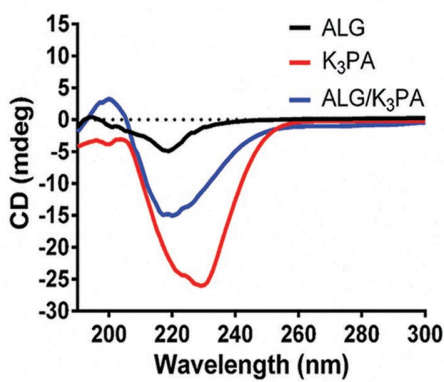

(c)
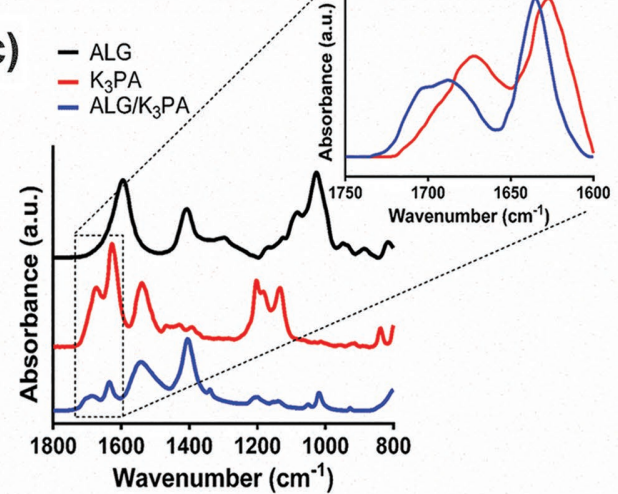
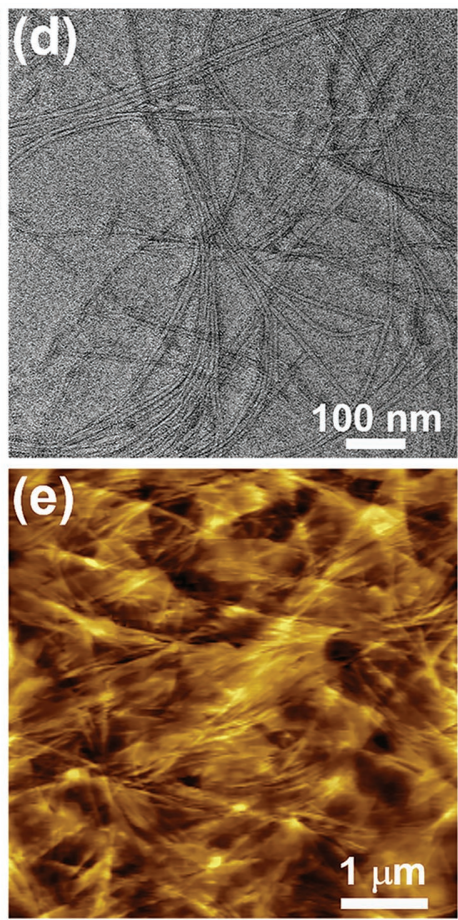

Figure 1. Characterization of the individual ALG and $K_{3} P A$ molecules and $A L G / K_{3} P A$ system (1:1 volume ratio). a) Chemical structures of the $K_{3} P A$ and ALG molecules and schematic representation of the assembly mechanism behind the formation of the ALG/K $\mathrm{PA}_{3}$ supramolecular system. $b, c)$ Secondary structure analysis of individual ALG and $K_{3} P A$ molecules as well as of the ALG/K ${ }_{3} P A$ system (1:1 volume ratio) by CD and FTIR spectroscopy, respectively, showing a $\beta$-sheet secondary structure for the $A L G / K_{3} P A$ mixture. d,e) Representative TEM and AFM images of the ALG $/ K_{3}$ PA (1:1, v/v ratio) nanofibrous structure, respectively.

$\mathrm{K}_{3}$ PA molecule showed that the purity of the sample was higher than $90 \%$ (Figure S1, Supporting Information).

Following the synthesis and purification of the PA molecule, its secondary structure and conformation was investigated using spectroscopic techniques, including circular dichroism (CD) and attenuated total reflectance-Fourier transform infrared (ATR-FTIR) spectroscopy. Typically, in CD spectra the $\beta$-sheet formation is assessed by the appearance of a negative minimum at $216 \mathrm{~nm}$ and a positive maximum at $195 \mathrm{~nm} \cdot{ }^{[20]}$ As can be seen from the visualization of Figure 1b, the PA molecule in solution adopted mostly a random coil configuration at the slightly acidic working $\mathrm{pH}$ of 5.5 , with two negative minima at around 195 and $225 \mathrm{~nm}$. The quantitative analysis of the spectrum and the accurate secondary structure prediction was performed according to the literature and confirmed such behavior (Figure S2, Supporting Information). ${ }^{[21]}$ The CD spectra of the ALG $/ K_{3}$ PA system in solution (1:1 v/v ratio) revealed a negative peak near $216 \mathrm{~nm}$ and a positive peak at $\approx 195 \mathrm{~nm}$, features that are assigned to the typical formation of $\beta$-sheet secondary structure configurations. ${ }^{[20]}$ Moreover, when the aqueous solution containing the PA molecule was mixed with the solution of the oppositely charged ALG biopolymer, the formation of aggregates was clearly observed by naked eye. As expected, the CD spectra of solely ALG solution did not exhibit any characteristic signal of a secondary structure organization.

Complementary to the CD analysis, ATR-FTIR measurements were also performed on dry films to examine the characteristic bands of individual ALG and $\mathrm{K}_{3} \mathrm{PA}$ molecules, as well as of the $A L G / K_{3}$ PA system, and to assess the possible $\beta$-sheet structural organization at pH 5.5 (Figure 1c). The FTIR spectrum of ALG biopolymer reveals well-defined absorption bands at $\approx 1595$ and $1415 \mathrm{~cm}^{-1}$, which are assigned to the asymmetric and symmetric axial deformations of the carboxylate anion (-COO- stretching vibration). Moreover, it also shows peaks in the range $950-1200 \mathrm{~cm}^{-1}$, which are due to the skeletal vibrations of the saccharide rings (asymmetric $\mathrm{C}-\mathrm{O}-\mathrm{C}$ stretching vibration). ${ }^{[22]}$ The spectrum of $\mathrm{K}_{3} \mathrm{PA}$ molecule shows a strong and sharp band at $\approx 1625 \mathrm{~cm}^{-1}$ (amide I band), which indicates a $\beta$-sheet secondary structure. ${ }^{[23]}$ The absence of a band near $1695 \mathrm{~cm}^{-1}$ (characteristic of antiparallel $\beta$-sheet networks) suggests that $\mathrm{K}_{3} \mathrm{PA}$ adopts a $\beta$-sheet secondary structure with a parallel orientation. In addition, the spectrum also shows two bands at $\approx 1675$ and $1540 \mathrm{~cm}^{-1}$, assigned to both lysine side chains and amide II band (mainly $\mathrm{N}-\mathrm{H}$ bending but also $\mathrm{C}-\mathrm{N}$ stretching), respectively. The spectrum of the ALG/K $\mathrm{K}_{3}$ PA system (1:1 v/v ratio) shows the bimodal amide I region between 1600 and $1700 \mathrm{~cm}^{-1}$ (composed mainly of $-\mathrm{C}=\mathrm{O}$ stretching), which provides valuable information related with the secondary structural organization of the peptide assemblies. The deconvolution of the amide I region reveals one peak position at $1635 \mathrm{~cm}^{-1}$ (amide $\mathrm{I}_{\mathrm{II}}$ ) as well as a shoulder peak near $1695 \mathrm{~cm}^{-1}$ (amide $\mathrm{I}_{\mathrm{I}}$ ), which indicates the formation of a hydrogen bonding $\beta$-sheet network with preferentially an antiparallel orientation. ${ }^{[23,24]}$ Similar to the $\mathrm{K}_{3} \mathrm{PA}$ molecule, the spectrum of the mixture 
also shows two bands near 1675 and $1540 \mathrm{~cm}^{-1}$. In addition, the spectrum of the $\mathrm{ALG} / \mathrm{K}_{3} \mathrm{PA}$ system revealed the presence of peaks that were also identified in the spectrum of the ALG molecule, including the peaks at $1415 \mathrm{~cm}^{-1}$ (-COO- stretching) and $1020 \mathrm{~cm}^{-1}$ (asymmetric $\mathrm{C}-\mathrm{O}-\mathrm{C}$ stretching). Overall, the ATR-FTIR measurements confirmed the results gathered by CD spectra, suggesting the formation of $\beta$-sheet secondary structures in the assemblies.

The results presented so far demonstrate the formation of ALG $/ K_{3}$ PA system through the interaction between ALG and $\mathrm{K}_{3}$ PA molecules. However, at this point it was unclear whether the main driving force leading to the formation of such system was of electrostatic nature. Hence, the electrical charge and possible interaction between ALG and $\mathrm{K}_{3} \mathrm{PA}$ molecules at the working $\mathrm{pH}$ of 5.5 was assessed by measuring the $\zeta$-potential of both solutions. The $\zeta$-potentials of the ALG and $\mathrm{K}_{3} \mathrm{PA}$ materials in $0.1 \mathrm{M}$ acetate buffer solution at $\mathrm{pH} 5.5$ were found to be $-31.0 \pm 2.1$ and $+22.8 \pm 2.9 \mathrm{mV}$, respectively, thus confirming the anionic and cationic nature of ALG and $\mathrm{K}_{3} \mathrm{PA}$ solutions, respectively at $\mathrm{pH}$ 5.5. According to the gathered values, we postulate that the negatively charged ALG and the positively charged $\mathrm{K}_{3} \mathrm{PA}$ molecules could be used to successfully form hybrid self-assembled systems and, possibly, buildup hybrid supramolecular multilayered assemblies making use of the electrostatic-driven LbL assembly interactions between the oppositely charged materials.

The morphology of the polysaccharide/peptide amphiphile supramolecular system, formed by the coassembly of negatively charged ALG and oppositely charged $\mathrm{K}_{3} \mathrm{PA}$ molecules, was assessed by TEM (Figure 1d and Figure S3, Supporting Information) and AFM (Figure 1e and Figure S4, Supporting Information), which clearly revealed the nanostructured dimensions and 1D nanofibrous network of the assembly formed by these two molecules. The individual fibers were found to be a few micrometers in length and $\approx 6-10 \mathrm{~nm}$ in width (see the histogram of the diameter distribution of the nanofibers formed by the ALG/ $\mathrm{K}_{3} \mathrm{PA}$ supramolecular system in Figure S3f, Supporting Information). The imaging results are in good agreement with the CD and FTIR data, as nanofiber networks are typically formed by $\beta$-sheet secondary structures. ${ }^{\left[{ }^{[c]}\right]}$ The morphology and structural features of the individual ALG and $\mathrm{K}_{3} \mathrm{PA}$ molecules were also examined by AFM (Figure S4, Supporting Information). As it is clear from the visualization of Figure S4d,e (Supporting Information), the individual $\mathrm{K}_{3} \mathrm{PA}$ molecule does not lead to the formation of nanofibers at the working $\mathrm{pH}$ of 5.5 , thus revealing that oppositely charged molecules are essential to stabilize the system, trigger the self-assembly behavior, and promote nanofiber formation. To further investigate the key role of the electrostatic interactions on the polysaccharide/ peptide amphiphile assembly process, the positively charged $\mathrm{K}_{3} \mathrm{PA}$ molecule was combined with a same charge molecule, namely positively charged chitosan $(\mathrm{CHT}$; $\zeta$-potential $=$ $+22.2 \pm 1.2 \mathrm{mV}$ at $\mathrm{pH}$ 5.5). The morphology of the $\mathrm{CHT} / \mathrm{K}_{3} \mathrm{PA}$ system was examined by TEM and did not show any fiber formation (Figure S3e, Supporting Information). In such case, the lack of visible interaction when combining both positively charged materials (no aggregates were formed after combining the CHT and $\mathrm{K}_{3}$ PA solutions that could be seen by naked eye) indicates that attractive electrostatic interactions are pivotal for the formation of $\beta$-sheet secondary structures and for promoting nanofiber formation.

\subsection{Buildup and Characterization of Hybrid $A L G / K_{3} P A$ Supramolecular Multilayered Assemblies}

In the next step, the possible buildup of the hybrid supramolecular multilayered films, through the sequential adsorption of oppositely charged ALG and $\mathrm{K}_{3} \mathrm{PA}$ molecules, was assessed in situ with the QCM-D technique by applying an alternating electric field across the gold-coated quartz crystal sensor. ${ }^{[25]}$ This technique is more than a mass sensing device as it simultaneously allows us to detect minute changes in hydrodynamic mass (adsorbed material plus coupled water) in the order of nanograms per square centimeter, due to changes in the resonance frequency of the quartz sensor, as well as measure the viscoelastic properties of the adsorbed films making use of the energy dissipated in the mechanical oscillation of the crystal. ${ }^{[25,26]}$

Figure 2a depicts the normalized frequency $\left(\Delta f_{n} / n\right)$ and dissipation factor $\left(\Delta D_{n}\right)$ changes obtained at the 7 th overtone ( $n=7 ; 35 \mathrm{MHz}$ ) during the construction of five bilayers of ALG/ $\mathrm{K}_{3} \mathrm{PA}$ films onto the poly(ethyleneimine) (PEI)-functionalized gold-plated quartz crystal substrates. The successive decrease in the $\Delta f_{7} / 7$ as a function of time after the injection of each building block onto the Au-plated quartz crystal surface not only corroborates the deposition of the materials and, thus, increase of adsorbed mass at every stage of the adsorption process but also indicates a gradual, stable, and successful growth of the nanostructured multilayered thin film. However, it is noteworthy that a long adsorption time was needed for the deposition of $\mathrm{K}_{3} \mathrm{PA}$ molecule. Furthermore, it is clear that $\mathrm{K}_{3} \mathrm{PA}$ experienced a systematically slower attachment when compared with ALG (see Figure S5, Supporting Information), thus indicating that the adsorption kinetics of ALG and $\mathrm{K}_{3}$ PA were different.
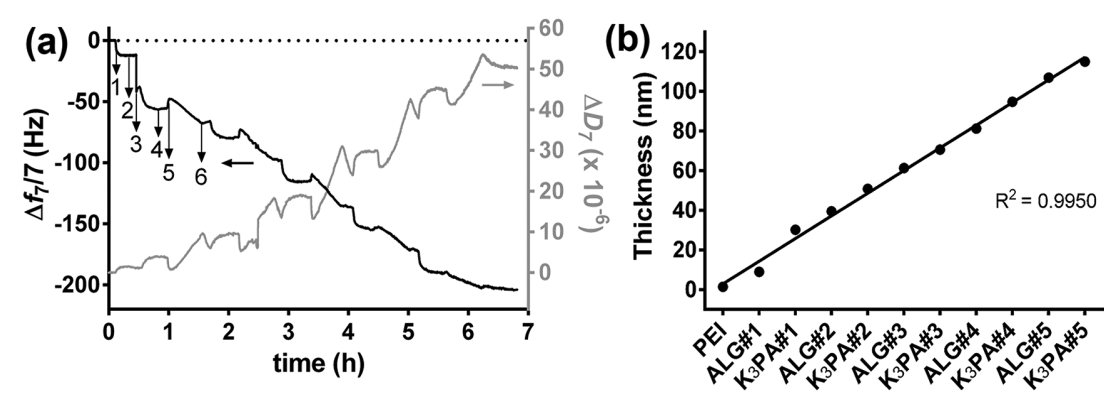

Figure 2. Buildup assessment of $\mathrm{PEI} /\left(\mathrm{ALG} / \mathrm{K}_{3} \mathrm{PA}\right)_{5}$ multilayered thin films onto gold-coated quartz crystal sensors. a) QCM-D monitoring of the normalized frequency $\left(\Delta f_{n} / n\right)$ and dissipation $\left(\Delta D_{n}\right)$ shifts, obtained at the seventh overtone $(n=7 ; 35 \mathrm{MHz})$, as a function of time for the $\mathrm{LbL}$ deposition of $\left(\mathrm{ALG} / \mathrm{K}_{3} \mathrm{PA}\right)_{5}$ bilayers onto PEl-functionalized gold-coated quartz crystal sensors and intermediate rinsing steps. Numbers refer to the adsorption of PEI (1), ALG (3), $K_{3} P A$ (5), and rinsing steps $\left(2,4\right.$, and 6). b) Cumulative thickness evolution for the $\mathrm{PEI} /\left(\mathrm{ALG} / \mathrm{K}_{3} \mathrm{PA}\right)_{5}$ multilayered film, estimated using the Voigt-based viscoelastic model. The black line represents the linear regression fit accompanied by the corresponding coefficient of determination $\left(R^{2}=0.9950\right)$. 
On the other hand, the continuous increase in the $\Delta D_{7}$ reveals the viscoelastic behavior of the adsorbed layers, indicating that the multilayered film is not rigid and shows damping properties, similarly to most polymeric systems. ${ }^{[25,27]}$ Moreover, with the increase in the energy dissipation values after each deposition step, the overtones also became separated (Figure S6, Supporting Information), which is a characteristic behavior of a soft and hydrated film. Moreover, such behavior suggests that the viscoelastic properties of the adsorbed films are not constant throughout the assembly process. ${ }^{[28]}$ The sequential decrease of the frequency shift together with the increase of the energy dissipation implies that at the working $\mathrm{pH}$ of 5.5, the positively charged PA molecule $\left(\mathrm{pH}<\mathrm{p} K_{\mathrm{a}} \approx 10\right)^{[29]}$ adsorbed onto the underlying negatively charged ALG surface $\left(\mathrm{pH}>\mathrm{p} K_{\mathrm{a}}\right.$ $\approx 3.38$ or 3.65 for mannuronic and guluronic acid residues, respectively). ${ }^{[30]}$ Such behavior confirms the effective interaction between the two molecules and the successful and stable step-by-step growth of supramolecular nanostructured multilayered systems comprising low- and high-molecular-weight materials making use of electrostatic interactions. Moreover, after the deposition of each layered material, i.e., ALG and $\mathrm{K}_{3} \mathrm{PA}$, rinsing steps were applied in order to remove weakly adsorbed molecules. The washing steps led to negligible changes in the $\Delta f_{7} / 7$ and $\Delta D_{7}$ values, thus indicating the strong association of both materials onto the PEI-modified Au-coated quartz crystal sensor, the formation of a stable film, and the irreversible nature of the adsorption process. Such behavior constitutes a step forward recent reports which highlighted that small positively charged model peptides or drugs, including $\alpha$-melanocyte stimulating hormone, gentamicin and defensin, could not be freely embedded into polyelectrolyte multilayered (PEM) films ended-up with either a positive or negatively charged polyelectrolyte layer due to their lack of adsorption onto such surfaces caused by the fast diffusion of such molecules from the PEM film during the assembly process. ${ }^{[31]}$ Hence, it has been claimed that free positively charged low-molecular-weight molecules, i.e., low-molecular-weight molecules that are not covalently couple to high-molecular-weight polymeric materials, could not function as stable building blocks in an LbL film. Furthermore, the absence of strong attractive interactions with oppositely charged polymeric materials did not lead to a successful and stable film growth. Indeed, the fabrication of stable PEM films incorporating the above-mentioned small molecules has been only achieved by first covalently binding them to polymeric materials, following by their incorporation into the PEM film. ${ }^{[32]}$

The QCM-D data were also used to estimate the thickness variations of the multilayered film at each adsorption step using the Voigt-based viscoelastic model. ${ }^{[33]}$ The cumulative thickness evolution for the PEI/(ALG/ $\left.\mathrm{K}_{3} \mathrm{PA}\right)_{5}$ multilayered film is shown in Figure 2b. It can be seen that the hydrodynamic thickness increased linearly while increasing the adsorption cycles, which corroborates the increase in the $-\Delta f_{7} / 7$ and $\Delta D_{7}$ values. After the buildup of ten $A L G / K_{3}$ PA layers the multilayered film reached to a final thickness of $115 \mathrm{~nm}$, corresponding to a thickness of $\approx 10-12 \mathrm{~nm}$ per each adsorbed layer.

In order to assess the key influence of the electrostatic forces on the successful step-by-step buildup of the hybrid supramolecular multilayered thin films, another LbL formulation consisting of materials exhibiting the same charge at $\mathrm{pH} 5.5$ (working conditions), namely CHT biopolymer and $\mathrm{K}_{3} \mathrm{PA}$, was tested. Figure S7 (Supporting Information) shows the $\Delta f_{7} / 7$ and $\Delta D_{7}$ curves as a function of the adsorption time for the buildup of nanostructured multilayered thin films comprising $\mathrm{CHT}, \mathrm{K}_{3} \mathrm{PA}$, and ALG multilayers onto the Aucoated quartz substrate (herein denoted as $\left(\mathrm{CHT} / \mathrm{K}_{3} \mathrm{PA}\right)_{3} /(\mathrm{ALG} /$ $\left.\mathrm{K}_{3} \mathrm{PA}\right)_{3}$ ). In opposition to that found for the buildup of the PEI/ $\left(\mathrm{ALG} / \mathrm{K}_{3} \mathrm{PA}\right)_{5}$ supramolecular multilayered films, in which a successful and stable multilayered growth was discerned, the lack of adsorption of positively charged $\mathrm{K}_{3} \mathrm{PA}$ onto positively charged CHT-modified surfaces at $\mathrm{pH} 5.5$ reveals that the selfassembling peptide amphiphile per se does not lead to the successful and effective growth of multilayered films. Although not successful, we proceeded with the assembly process by assessing the fabrication of $\left(\mathrm{ALG} / \mathrm{K}_{3} \mathrm{PA}\right)_{3}$ multilayers over the $\left(\mathrm{CHT} / \mathrm{K}_{3} \mathrm{PA}\right)_{3}$-modified Au-plated quartz substrate. In opposition to that found for the multilayered film comprising solely $\left(\mathrm{CHT} / \mathrm{K}_{3} \mathrm{PA}\right)_{3}$ bilayers, the subsequent addition of $\left(\mathrm{ALG} / \mathrm{K}_{3} \mathrm{PA}\right)_{3}$ bilayers onto the system led to a successful and stable multilayer growth. Therefore, these results demonstrate that attractive electrostatic interactions between ALG and $\mathrm{K}_{3}$ PA molecules are essential to trigger the self-assembly of PA molecules and promote the successful and stable multilayered growth.

Overall, the results gathered through QCM-D measurements demonstrate that stable hybrid supramolecular multilayered thin films consisting of ALG and $\mathrm{K}_{3} \mathrm{PA}$ molecules can be successfully conceived at the nanometric-scale using the selfassembly and electrostatic-driven LbL assembly approaches.

Then, the morphology and structural features of the supramolecular ALG $/ \mathrm{K}_{3}$ PA nanostructured multilayered thin films after assembly onto the PEI-functionalized Au-coated substrates were assessed by imaging techniques, including AFM (Figure 3) and SEM (Figure 4). Figure 3 displays the AFM topographic images obtained for the bare Au substrate (Figure 3a), Au substratemodified with PEI and ALG monolayers (Figure 3b) as well as $\left(\mathrm{ALG} / \mathrm{K}_{3} \mathrm{PA}\right)_{2}$ (Figure $3 \mathrm{c}$ ) and $\left(\mathrm{ALG} / \mathrm{K}_{3} \mathrm{PA}\right)_{5}$ (Figure $\left.3 \mathrm{~d}\right)$ multilayered films deposited at $\mathrm{pH} 5.5$ over the Au/PEI substrate. The image for bare $\mathrm{Au}$ (Figure 3a) revealed surface scratches and pinholes that were filled after the deposition of PEI and ALG layers (Figure 3b). Moreover, upon the adsorption of a two-bilayer ALG $/ \mathrm{K}_{3}$ PA film, the formation of self-assembling PA nanofibers could be seen in great detail over the polymeric background (Figure 3c). Interestingly, even at such low number of bilayers, the individual PA nanofibers tended to associate into nanofiber bundles. Such behavior could be assigned to the attractive electrostatic forces between the negatively charged ALG biopolymer and the oppositely charged $\mathrm{K}_{3} \mathrm{PA}$, which not only diminished in great extension the repulsion between the PA molecules, bearing positive charges at $\mathrm{pH} 5.5$, but also triggered the self-assembly of the PA via charge neutralization and subsequently led to the formation of nanofibrous networks. Hence, it seems clear that oppositely charged molecules play a pivotal role on promoting the association of individual PA nanofibers and nanofibrous network formation as well as on stabilizing the supramolecular system. However, it is worth noting that besides attractive electrostatic interactions, other driving forces, including hydrophobic interactions of the PA alkyl tails, hydrogen bonding interactions among the $\beta$-sheet forming peptide segment, and 

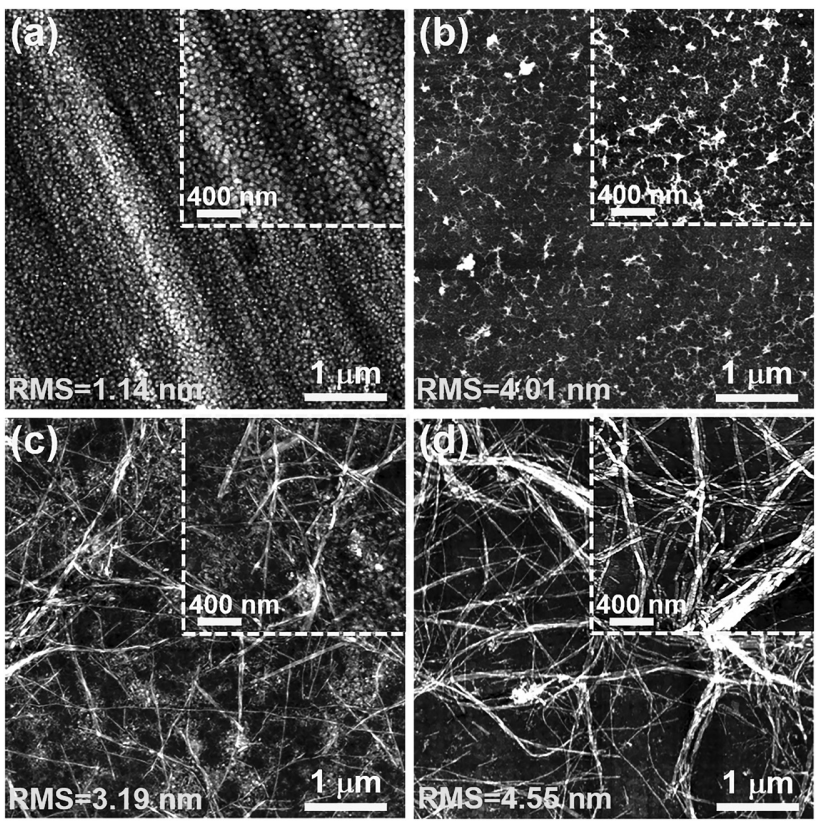

Figure 3. Representative AFM topographic images taken in air for a) $A u$ b) $\mathrm{Au} / \mathrm{PEI} / \mathrm{ALG}, \mathrm{c}) \mathrm{Au} / \mathrm{PEI} /\left(\mathrm{ALG} / \mathrm{K}_{3} \mathrm{PA}\right)_{2}$, and d) $\mathrm{Au} / \mathrm{PEI} /\left(\mathrm{ALG} / \mathrm{K}_{3} \mathrm{PA}\right)_{5}$ films, showing the root-mean-square (RMS) roughness of all surfaces. The regions displayed were representative of the full samples. The AFM amplitude images and height profiles have been also extracted in each case and can be found in Figure S8 (Supporting Information). The images scan sizes are $5 \times 5 \mu \mathrm{m}^{2}$ (main images) and $2 \times 2 \mu \mathrm{m}^{2}$ (insets).

electrostatic repulsion between the charged amino acids may also play an important role on the aggregation of the PA molecules and nanofibrous network formation.
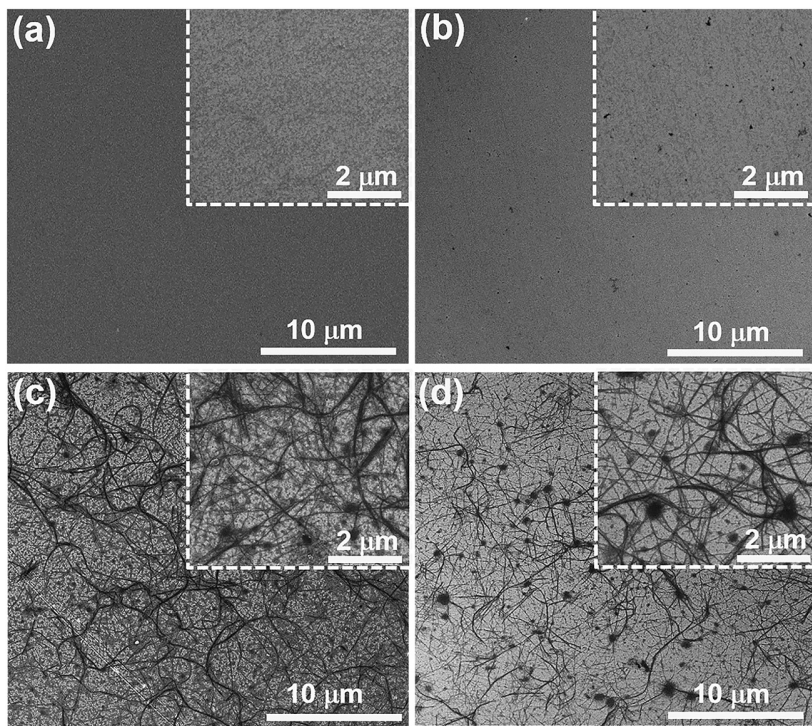

Figure 4. SEM images taken in high vacuum ( $20 \mathrm{kV})$ and secondary electrons mode over different regions of the a) Au substrate modified with b) $\mathrm{PEI} / \mathrm{ALG}, \mathrm{c}) \mathrm{PEI} /\left(\mathrm{ALG} / \mathrm{K}_{3} \mathrm{PA}\right)_{2}$, and d) $\mathrm{PEI} /\left(\mathrm{ALG} / \mathrm{K}_{3} \mathrm{PA}\right)_{5}$ multilayers. The regions displayed were representative of the full samples. The magnification factor was $10000 \times$ (main images) and $50000 \times$ (insets) and the working distance (WD) $5.1 \mathrm{~mm}$ in both cases.
Moreover, a denser network of nanofibers could be seen upon increasing the number of layer pairs to five bilayers, $\left(\mathrm{ALG} / \mathrm{K}_{3} \mathrm{PA}\right)_{5}$ (Figure $3 \mathrm{~d}$ ). Bundles of individual PA nanofibers interact with repeating large ALG macromolecule to form nanofibrous bundles. The progressive bundling of PA nanofibers into high-aspect-ratio nanofibers formed a dense nanofibrous network, which covered the entire surface. These networks assemble spontaneously after the coassembly of the oppositely charged molecules. Indeed, with the increase in the number of bilayers, there is an increase in the electrostatic screening of positive charges on the small $\mathrm{K}_{3} \mathrm{PA}$ molecules by oppositely charged large ALG macromolecule. Such charge screening is expected to trigger PA self-assembly capability and promote further nanofiber bundling, thus being expected to result in more robust nanofiber networks. However, further experiments would be needed to undoubtedly make considerations on the robustness of such nanofibrous structures.

Very interestingly, no sign of the polymeric background was seen, which confirmed the progressive bundling of PA nanofibers into larger nanofibrous bundles, which could have implications in several properties, including cell behavior. These findings were supported by the height profiles extracted from the AFM images, which revealed an increase in the height of the nanofibers covering the surface upon increasing the number of $\left(\mathrm{ALG} / \mathrm{K}_{3} \mathrm{PA}\right)_{n}$ bilayers (Figure S8, Supporting Information). Agreeing with that, the root-mean-square (RMS) surface roughness increased from $3.19 \mathrm{~nm}$, for the films consisting of two ALG $/ \mathrm{K}_{3} \mathrm{PA}$ layer pairs, to $4.55 \mathrm{~nm}\left(\left(\mathrm{ALG} / \mathrm{K}_{3} \mathrm{PA}\right)_{5}\right.$ bilayers), revealing that the surface became rougher with the increase in the number of ALG/K ${ }_{3}$ PA bilayers (Figure 3).

The nanostructured assemblies were further inspected by SEM, as shown in Figure 4. The SEM images corroborated the AFM findings by showing the formation of nanofibers after the assembly of two $\mathrm{ALG} / \mathrm{K}_{3} \mathrm{PA}$ layer pairs (Figure $4 \mathrm{c}$ ). Moreover, a nanofibrous network with a denser network of nanofibers could be seen upon increasing the number of ALG/ $\mathrm{K}_{3}$ PA bilayers (Figure $4 \mathrm{~d}$ ). Such behavior may be ascribed to the intensive association/aggregation of PA molecules upon increasing the number of PA and ALG biopolymer layers. Hence, the neutralization of the positively charged PA residues by oppositely charged ALG macromolecules together with the number of layer pairs are essential for promoting the efficient aggregation of PA molecules, and further formation of nanofibrillar functional structures. Moreover, the enlarged SEM images in Figure 4c,d (see figure insets) clearly show dark spots at the interstices of nanofibers, which may be assigned to aggregates of the ALG biopolymer that bind or glue neighboring PA nanofibers together and form a nanofibrous network. A closer inspection of the Figure 4c,d revealed that such aggregates are increasingly larger and exist in higher number upon increasing the number of $\mathrm{ALG} / \mathrm{K}_{3}$ PA bilayers. Such behavior may be ascribed to the increasing number of ALG layers that contribute as enhanced junction points to bundle individual PA nanofibers into a nanofibrous network. It is worth noting that, although the PA molecule used in this study does not contain any kind of bioactive moiety, such supramolecular nanofibrous networks resemble the fibrous architecture and the capacity to signal cells of the native ECM. Hence, such nanostructures reveal a great promise to support and guide cell 

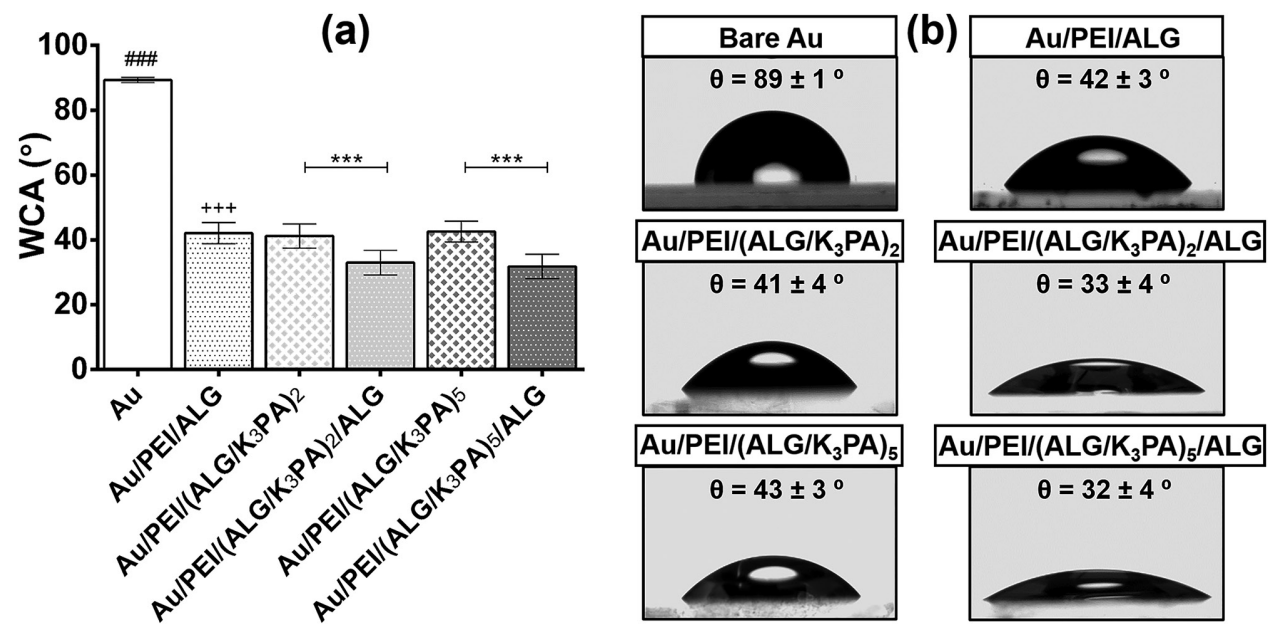

Figure 5. a) Water contact angle (WCA) of uncoated and coated Au surfaces. Data are presented as mean \pm standard deviation ( $n=3$, per condition; statistically significant differences between $\mathrm{K}_{3} \mathrm{PA}$ and ALG-ending films were noted for ( $\left.* * * *\right) p<0.001$; significant differences between all conditions and uncoated Au surface were found for (\#\#\#) $p<0.001$; significant differences between the sample formulations ended in ALG and Au/PEI/ALG were obtained for $(+++) p<0.001$. b) Representative images of water droplets on uncoated and coated Au surfaces.

behavior in the context of tissue engineering and regenerative medicine strategies.

To further assess the modification of the surfaces upon increasing the number of adsorbed layers and the role of the end layer of the multilayered coatings, their wettability properties were studied by WCA measurements (Figure 5). Although both $\mathrm{K}_{3} \mathrm{PA}$ - and ALG-ending films show a hydrophilic behavior, regardless of the number of bilayers, the ones ending in ALG retained a slightly more wettable state. The higher contact angle values obtained for $\mathrm{K}_{3} \mathrm{PA}$-ending films can be assigned to the hydrophobic alkyl tail and hydrophobic amino acid domains presented in the peptide structures which turn them slightly more hydrophobic than the similar films ending in ALG. A similar behavior has been previously reported for nanostructured multilayered coatings comprising CHT biopolymer and elastin-like recombinamers. ${ }^{[34]}$ At this step, it is worth noting that such slight differences could be important in instructing cell behavior, as will be later demonstrated in this paper. The comparison of all ALG-ending films denotes that a higher contact angle was obtained for the deposition of ALG over the PEImodified Au substrate. This behavior can be explained by the fact that in such film the ALG biopolymer is directly adsorbed on a single PEI monolayer previously deposited over the hydrophobic Au substrate. Hence, there is a great influence of the underlying Au substrate on the ALG wettability properties.

\subsection{In Vitro Biological Performance of Hybrid $A L G / K_{3} P A$ Supramolecular Multilayered Assemblies}

\subsubsection{C2C12 Viability and Morphology}

Material-cell interactions play an important role on the regulation of cellular events, including adhesion, growth, proliferation, organization, and differentiation. For that, materials mimicking the ECM may be chosen as a good strategy to provide a suitable environment for cells to adhere, grow, gain their phenotype, and differentiate. Herein, the in vitro biological performance of the developed polysaccharide/peptide amphiphile hybrid supramolecular nanoassemblies ending in $\mathrm{K}_{3} \mathrm{PA}$ and ALG was assessed in the presence of $\mathrm{C} 2 \mathrm{C} 12$ mouse myoblast model cells. Such study enabled us to investigate the role of the end layer of the multilayered coatings on cell behavior and ultimately their suitability as matrices for future tissue engineering strategies. Moreover, these cells were also seeded on uncoated surfaces, to evaluate the coating effect and prove its superior performance on cellular viability, metabolic activity, and morphology. Although other cell types could be explored, in this work we have chosen C2C12 myoblast cells, which are normally used as a model system in skeletal muscle regeneration and differentiation studies, to assess the suitability of the multilayered coatings to support the growth and differentiation of the cells into myotubes. ${ }^{[35]}$ The cellular metabolic activity was assessed in the different surfaces at three different time points $(1,3$, and 5 d) through a (3-(4,5-dimethylthiazol-2-yl)5-(3-carboxymethoxyphenyl)-2-(4-sulfophenyl)-2H-tetrazolium) (MTS) assay (Figure 6). The results obtained after $1 \mathrm{~d}$ reveal that the cell activity was very similar in all studied surfaces. However, after $3 \mathrm{~d}$ of culture, the two bilayered films ending in $\mathrm{K}_{3} \mathrm{PA}$ presented higher cellular metabolic activity than the ones ending in ALG-Au/PEI/ALG and $\mathrm{Au} / \mathrm{PEI} /\left(\mathrm{ALG} / \mathrm{K}_{3} \mathrm{PA}\right)_{2} /$ ALG films, respectively, which demonstrate the potential of PAs for biological and biomedical applications. After $5 \mathrm{~d}$, both PA-ending coatings, i.e., $\mathrm{Au} / \mathrm{PEI} /\left(\mathrm{ALG} / \mathrm{K}_{3} \mathrm{PA}\right)_{2}$ and $\mathrm{Au} / \mathrm{PEI} /$ $\left(\mathrm{ALG} / \mathrm{K}_{3} \mathrm{PA}\right)_{5}$, showed higher metabolic activity values than the ones ending with an ALG layer-Au/PEI/ALG, Au/PEI/(ALG/ $\left.\mathrm{K}_{3} \mathrm{PA}\right)_{2} / \mathrm{ALG}$, and $\mathrm{Au} / \mathrm{PEI} /\left(\mathrm{ALG} / \mathrm{K}_{3} \mathrm{PA}\right)_{5} / \mathrm{ALG}$ films. Although ALG has been extensively reported in literature as a promising material for biomedical applications, its use alone cannot effectively promote cellular adhesion, ${ }^{[36]}$ thus supporting the abovementioned results. When ALG macromolecule was chosen as the end layer, the cells felt this material more than the underlying layers which may be assigned as the main reason for the differences found on the metabolic activity. In which concerns 


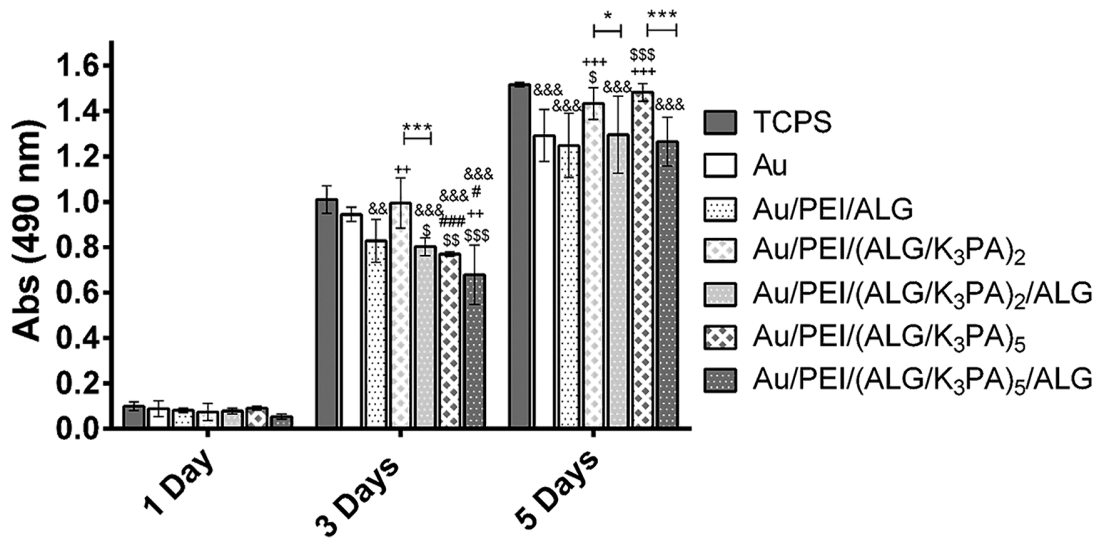

Figure 6. Cellular viability through the measurement of the absorbance of the metabolic activity of $\mathrm{C} 2 \mathrm{C} 12$ cells (MTS assay) seeded onto TCPS surfaces, and uncoated and coated Au surfaces as a function of the culture time (1,3, and $5 \mathrm{~d})$. Absorbance was read at $490 \mathrm{~nm}$. Significant differences between films ending in $\mathrm{K}_{3} \mathrm{PA}$ and ALG were found for $(*) p<0.05$ and $(* * *) p<0.001$. Significant differences between different conditions and uncoated $A u$ surfaces were found for (\$) $p<0.05,(\$) p<0.01$, and $(\$ \$) p<0.001$; significant differences were also obtained for $(+) p<0.05$ comparing the Au/PEI/ALG films with Au/PEI/(ALG/K $\left./ \mathrm{K}_{3} \mathrm{PA}\right)_{5} / \mathrm{ALG}$ films. Significant differences between different conditions and TCPS surfaces were found for $(\& \&) p<0.01$ and $(\& \& \&) p<0.001$. Data are presented as mean \pm standard deviation $(n=3)$.

to the number of bilayers, statistically significant differences were observed after $3 \mathrm{~d}$, with the two bilayered films presenting higher metabolic activity than the ones consisting of five bilayers. Nevertheless, no differences were discerned after $5 \mathrm{~d}$ of culture. However, after $5 \mathrm{~d}$ of culture, the metabolic activity and viability of $\mathrm{C} 2 \mathrm{C} 12$ cells adhered on $\mathrm{K}_{3}$ PA-ending films were higher than those on bare $\mathrm{Au}$ and ALG-ending surfaces, and similar to those on tissue culture polystyrene surfaces (TCPS; positive control). Overall, the results reveal that cells were able to remain viable in all surfaces up to $5 \mathrm{~d}$ in culture and that PAending films showed a higher cell viability.

These results agree quite well with previous reports, where self-assembled nanofibers sustained cell-matrix interactions at the molecular level resulting in better cellular adhesion, viability, proliferation, and differentiation. ${ }^{[11 b, 37]}$ Besides the surface chemistry and morphology, the aforementioned statistically significant differences in the wettability properties of the $\mathrm{K}_{3} \mathrm{PA}$ - and ALG-ending surfaces could have a key role in guiding cell fate, as hydrophilic coatings were already reported for their good impact on cell behavior. ${ }^{[38]}$ Nevertheless, highly hydrophilic (wettable) and high charge density surfaces can have the opposite effect. ${ }^{[35]}$ In addition, the positive charges on the self-assembling $\mathrm{K}_{3}$ PA molecule could also enhance cellmaterials interactions when compared with the high negatively charged ALG macromolecule, as previously reported. ${ }^{[39]}$

The cellular adhesion and morphology were also evaluated by fluorescence microscopy. In a preliminary assessment, the initial adhesion and morphology of $\mathrm{C} 2 \mathrm{C} 12$ cells seeded on the different surfaces was investigated after $4 \mathrm{~h}$ of culture (see Figure S9, Supporting Information). Even at such low culture time, the cells adhered to all surfaces and some differences in the number of cells attached to the different surface formulations could be observed. Initial cellular adhesion seems to be better for the bare $\mathrm{Au}$ when compared with the Au/PEI/ALG surface. On the other hand, $\mathrm{C} 2 \mathrm{C} 12$ cells cultured on $\mathrm{K}_{3} \mathrm{PA}$ - ending multilayered surfaces, i.e., $\mathrm{Au} / \mathrm{PEI} /$ $\left(\mathrm{ALG} / \mathrm{K}_{3} \mathrm{PA}\right)_{2}$ and $\mathrm{Au} / \mathrm{PEI} /\left(\mathrm{ALG} / \mathrm{K}_{3} \mathrm{PA}\right)_{5}$, showed a significant higher attached number of cells when compared with the $\mathrm{Au} / \mathrm{PEI} /$ ALG surface. Furthermore, the $\mathrm{K}_{3}$ PA-ending multilayered films revealed a similar number of attached cells when compared to the TCPS surface, thus revealing that $\mathrm{C} 2 \mathrm{C} 12$ cells adhere better to the films containing $\mathrm{K}_{3} \mathrm{PA}$ as the outer layer. Moreover, the characteristic morphology of undifferentiated $\mathrm{C} 2 \mathrm{C} 12$ is presented as star-like shape, ${ }^{[40]}$ and this morphology started to be observed after $4 \mathrm{~h}$ of culture. In general, these results are in good agreement with previous reports in the literature which postulate that surface topography and nanostructured surfaces play an important role on cellular adhesion. ${ }^{[41]}$ Besides the evaluation of the adhesion of myoblasts on TCPS surface, and uncoated and coated $\mathrm{Au}$ surfaces after $4 \mathrm{~h}$ of culture, the cellular morphology was also investigated for 1, 3, and $5 \mathrm{~d}$ (Figure 7). Since the first day after seeding, it can be seen that $\mathrm{C} 2 \mathrm{C} 12$ adhered and spread on the TCPS surface, as well as on the surface of the uncoated and coated Au substrates. At day 1, no differences were discerned in the morphology of $\mathrm{C} 2 \mathrm{C} 12$ cells seeded on the different surfaces, with cells showing a well-spread morphology. Nevertheless, the cells started to extend their filopodia and to communicate with each other. At day 3, the increase on cell density in all sample formulations is clearly noticed. Generally, C2C12 cells proliferated and migrated all over the different surfaces but some differences were denoted between the different conditions. For all coated-substrates conditions, the cells started to fuse with each other. Moreover, the cells seeded onto $\mathrm{K}_{3}$ PA-ending multilayered coatings seem to be more elongated, with filopodia being widespread preferentially on specific regions, than the ones ending in ALG. Again, at day 5 of culture, the cell density increased and $\mathrm{C} 2 \mathrm{C} 12$ cells seeded on TCPS surface, and uncoated and coated Au surfaces proliferated and formed a continuous monolayer of cells. At this time, cellular density seems to be higher on $\mathrm{K}_{3} \mathrm{PA}$-ending films, i.e., $\mathrm{Au} / \mathrm{PEI} /\left(\mathrm{ALG} / \mathrm{K}_{3} \mathrm{PA}\right)_{2}$ and $\mathrm{Au} / \mathrm{PEI} /\left(\mathrm{ALG} / \mathrm{K}_{3} \mathrm{PA}\right)_{5}$, corroborating the MTS assay. Moreover, when $\mathrm{K}_{3} \mathrm{PA}$ was chosen as the end layer, similar results to those obtained for TCPS surface were attained in terms of observed cellular density (Figure S10, Supporting Information). In summary, the obtained results show that the design and fabrication of nanolayered PA-based multilayered coatings seem to positively influence the in vitro cellular behavior, including cell adherence, spreading, and proliferation. These cellular events could be modulated by different surface characteristics as chemistry, wettability and topography. Although $\mathrm{K}_{3}$ PA does not present bioactive domains in its structure, it assigns to the surface a fiber-like topography where cells could sense a surface topography similar to native ECM, thus influencing the cellular behavior. ${ }^{[42]}$ The ECM topography is composed by nanofibers capable of supporting cells and providing instructive cues to guide cellular behavior. ${ }^{[43]}$ Mimicking the topography of ECM has been largely exploited on tissue 


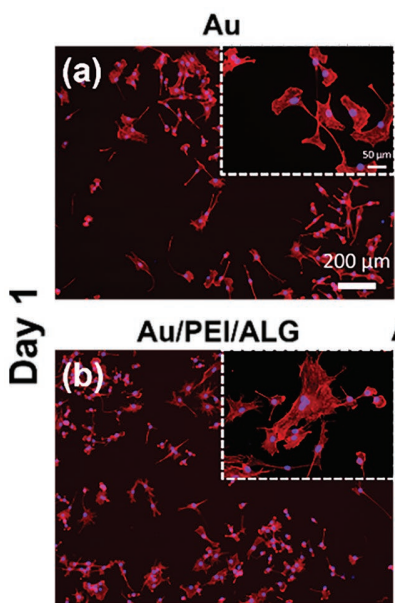

$\mathrm{Au} / \mathrm{PEI} /\left(\mathrm{ALG} / \mathrm{K}_{3} \mathrm{PA}\right)_{2}$
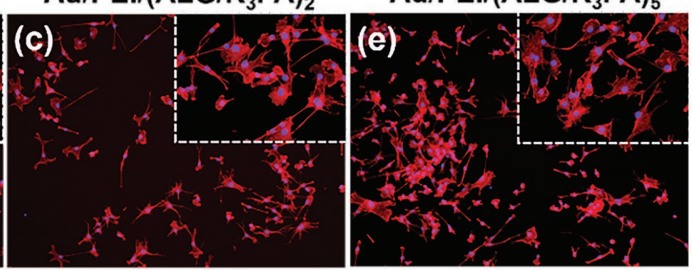

Au/PEI/(ALG/K ${ }_{3}$ PA) $)_{2} / A L G$ Au/PEI/(ALG/K $\left.{ }_{3} \mathrm{PA}\right)_{5} / \mathrm{ALG}$
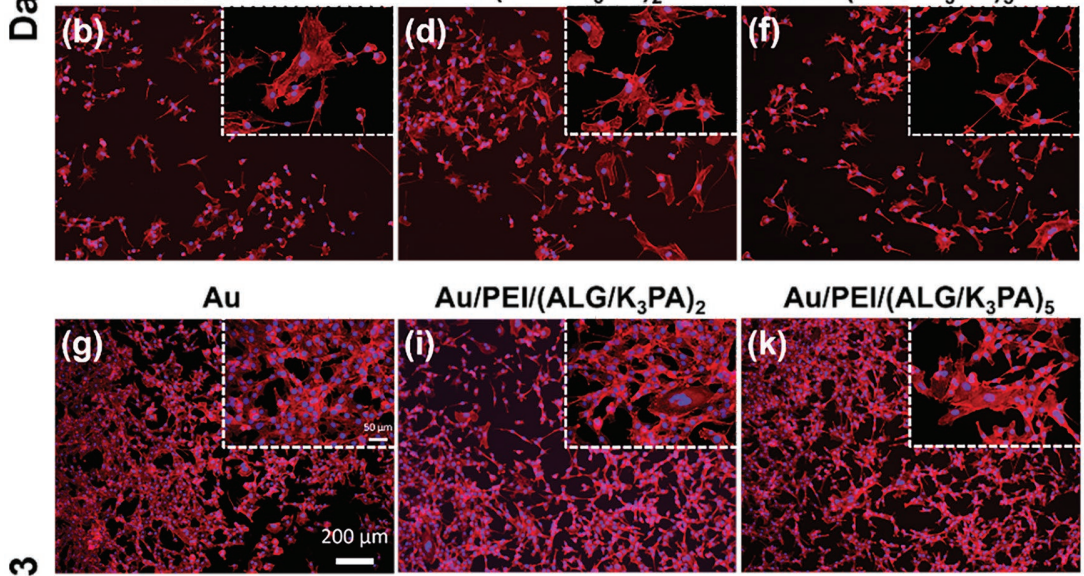

$\mathrm{Au} / \mathrm{PEI} /\left(\mathrm{ALG} / \mathrm{K}_{3} \mathrm{PA}\right)_{2}$

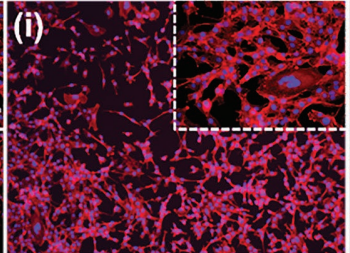

$\mathrm{Au} / \mathrm{PEI} /\left(\mathrm{ALG} / \mathrm{K}_{3} \mathrm{PA}\right)_{5}$

तั

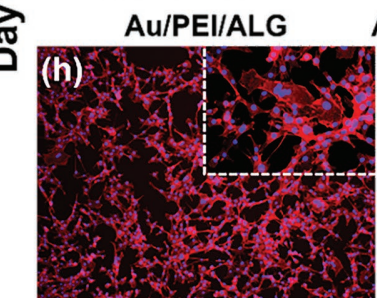

$\mathrm{Au} / \mathrm{PEI} /\left(\mathrm{ALG} / \mathrm{K}_{3} \mathrm{PA}\right)_{2} / \mathrm{ALG} \mathrm{Au} / \mathrm{PEI} /\left(\mathrm{ALG} / \mathrm{K}_{3} \mathrm{PA}\right)_{5} / \mathrm{ALG}$
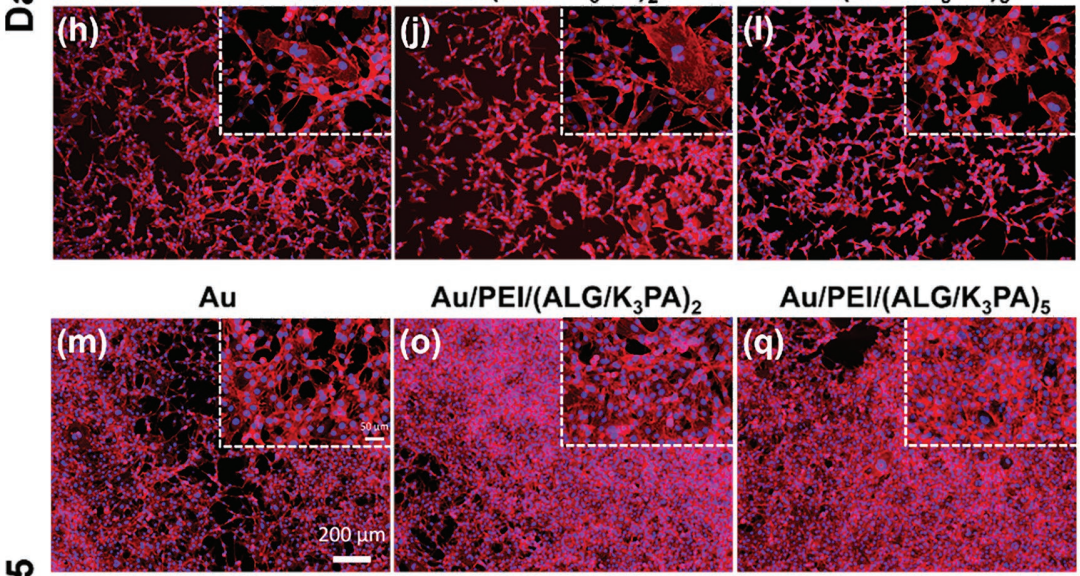

$\mathrm{Au} / \mathrm{PEI} /\left(\mathrm{ALG} / \mathrm{K}_{3} \mathrm{PA}\right)_{2}$

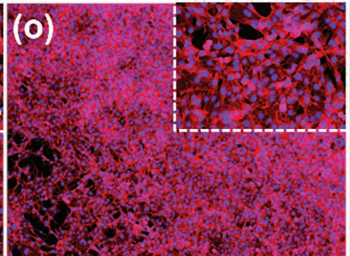

$\mathrm{Au} / \mathrm{PEI} /\left(\mathrm{ALG} / \mathrm{K}_{3} \mathrm{PA}\right)_{5}$

ลे

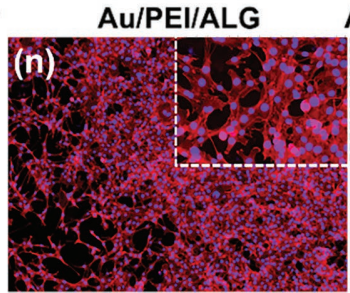

Au/PEI/(ALG/K PA $_{3}$ PALG Au/PEI/(ALG/K $\left./ \mathrm{K}_{3} \mathrm{PA}\right)_{5} / \mathrm{ALG}$

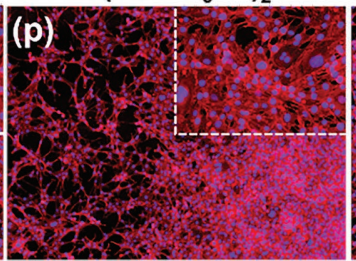

(a)

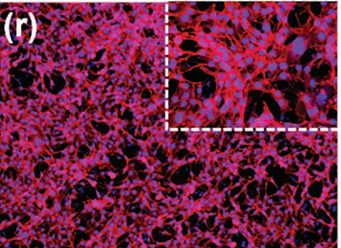

Figure 7. Representative fluorescence microscopy images of $\mathrm{C} 2 \mathrm{C} 12$ cells with nuclei stained with DAPI (blue) and F-actin filaments in the cytoskeleton with phalloidin (red) at 1, 3, and $5 \mathrm{~d}$ of culture on uncoated and coated Au surfaces: a,g,m) bare $A u, b, h, n) A u / P E I / A L G$, $\mathrm{c}, \mathrm{i}, \mathrm{o}) \mathrm{Au} / \mathrm{PEI} /\left(\mathrm{ALG} / \mathrm{K}_{3} \mathrm{PA}\right)_{2}$, d,j,p) Au/PEI/(ALG/K $\left.\left.\mathrm{K}_{3} \mathrm{PA}\right)_{2} / \mathrm{ALG}, \mathrm{e}, \mathrm{k}, \mathrm{q}\right) \mathrm{Au} / \mathrm{PEI} /\left(\mathrm{ALG} / \mathrm{K}_{3} \mathrm{PA}\right)_{5}$, and $\mathrm{f}, \mathrm{l}, \mathrm{r}) \mathrm{Au} / \mathrm{PEI} /\left(\mathrm{ALG} / \mathrm{K}_{3} \mathrm{PA}\right)_{5} / \mathrm{ALG}$. Scale bars represent $200 \mu \mathrm{m}$ (main images) and $50 \mu \mathrm{m}$ (inset images) in all images.

engineering field, ${ }^{[43 b]}$ as well as the use of the LbL technology to recreate a variety of cellular microenvironments. ${ }^{[44]}$ In this work, we observed that both $\mathrm{Au} / \mathrm{PEI} /\left(\mathrm{ALG} / \mathrm{K}_{3} \mathrm{PA}\right)_{2}$ and $\mathrm{Au} / \mathrm{PEI} /$
$\left(\mathrm{ALG} / \mathrm{K}_{3} \mathrm{PA}\right)_{5}$ films seem to present higher cellular density and better morphology than the remaining conditions.

\subsubsection{Myogenic Differentiation of $\mathrm{C} 2 \mathrm{C} 12$ Cells}

The myogenic differentiation of $\mathrm{C} 2 \mathrm{C} 12$ cells was evaluated by immunofluorescence staining for troponin $\mathrm{T}$, a well-characterized marker for myogenic differentiation of muscle cells. C2C12 cells seeded on uncoated and coated Au substrates were put to differentiate for $5 \mathrm{~d}$, using Dulbecco's modified Eagle's medium (DMEM) supplemented with $2 \%$ of horse serum to support a mature myogenic process. Figure 8 shows the immunofluorescence images, which are representative for each condition. For the different surfaces, C2C12 myoblasts proliferated and started to differentiate into mature and multinucleated myotubes, which is evident from the staining for troponin $\mathrm{T}$ (green). Moreover, some differences in terms of myogenic differentiation were observed between the myoblasts cultured on the different substrates. The C2C12 myoblast cells seeded on bare $\mathrm{Au}, \mathrm{Au} / \mathrm{PEI} /\left(\mathrm{ALG} / \mathrm{K}_{3} \mathrm{PA}\right)_{2}$, and $\mathrm{Au} / \mathrm{PEI} /$ $\left(\mathrm{ALG} / \mathrm{K}_{3} \mathrm{PA}\right)_{5}$ films differentiated into multinucleated myotubes, revealing a tube-like morphology. On the other hand, differentiated cells adhered on Au/PEI/ALG surface do not show a regular tube-like morphology. We postulate that this behavior could be related with the absence of a nanofibrous topography. Interestingly, C2C12 cultured on $\mathrm{Au} / \mathrm{PEI} /\left(\mathrm{ALG} / \mathrm{K}_{3} \mathrm{PA}\right)_{2} / \mathrm{ALG}$ and $\mathrm{Au} / \mathrm{PEI} /$ (ALG $\left./ \mathrm{K}_{3} \mathrm{PA}\right)_{5} / \mathrm{ALG}$ films also differentiated into mature myotubes with a tube-like morphology. We hypothesize that such behavior may be due to the increasing number of bilayers that greatly weakened the effect of the outermost layer.

To support these results, fusion index, troponin T-positive area, and myotube length were also determined with ImageJ software (Figure S11, Supporting Information). The fusion index (Figure S11a, Supporting Information) was significantly higher when the C2C12 myoblasts were seeded on the $\mathrm{Au} /$ $\mathrm{PEI} /\left(\mathrm{ALG} / \mathrm{K}_{3} \mathrm{PA}\right)_{2}$ films rather than on similar films ended in ALG-Au/PEI/(ALG/ $\left.\mathrm{K}_{3} \mathrm{PA}\right)_{2} / \mathrm{ALG}$. However, no significant differences were found when comparing the fusion index of cells cultured on $\mathrm{Au} / \mathrm{PEI} /$ $\left(\mathrm{ALG} / \mathrm{K}_{3} \mathrm{PA}\right)_{5}$ and $\mathrm{Au} / \mathrm{PEI} /\left(\mathrm{ALG} / \mathrm{K}_{3} \mathrm{PA}\right)_{5} /$ ALG films. These results agree quite well with the immunofluorescence images displayed in Figure 8. Furthermore, no significant differences were found for $\mathrm{C} 2 \mathrm{C} 12$ cells cultured on 


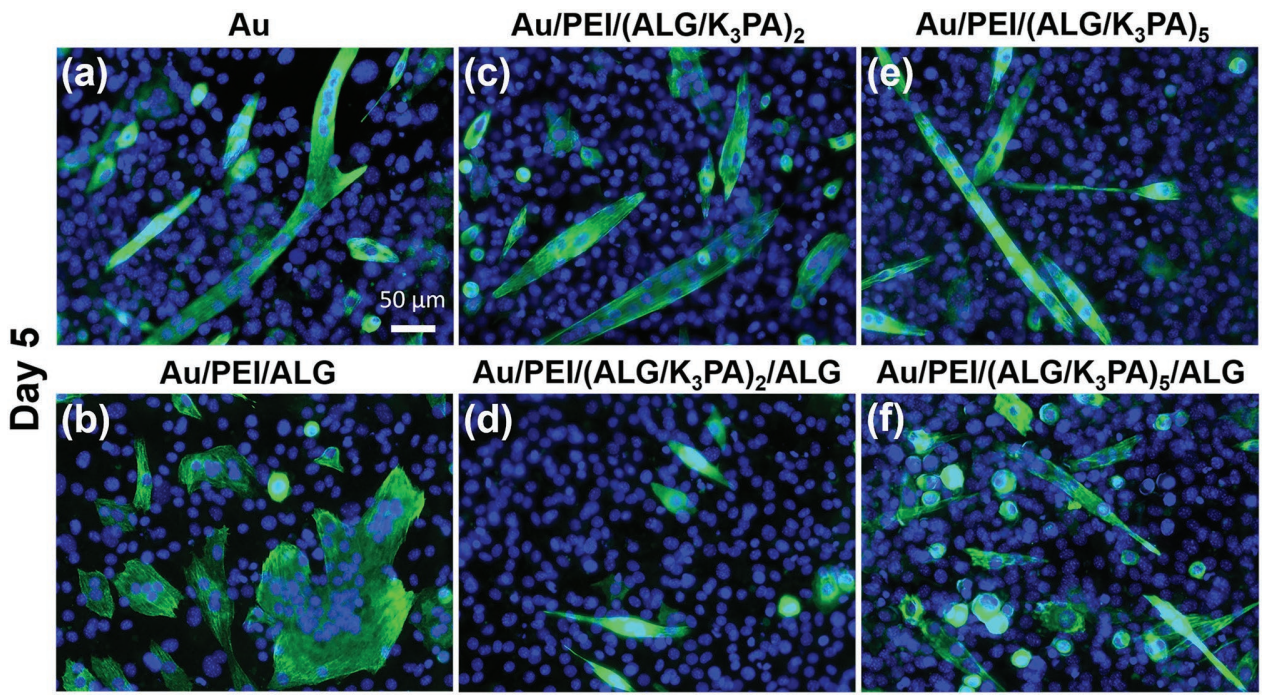

Figure 8. Representative immunofluorescence images of $\mathrm{C} 2 \mathrm{C} 12$ cells with myotubes stained with troponin $\mathrm{T}$ (green) and nuclei with DAPI (blue) at $5 \mathrm{~d}$ of culture on uncoated and coated Au surfaces, using differentiation medium (DM): a) bare Au, b) Au/PEI/ALG, c) Au/PEI/(ALG/K $\left.\left.{ }_{3} \mathrm{PA}\right)_{2}, \mathrm{~d}\right) \mathrm{Au} / \mathrm{PEI} /$ $\left.\left(\mathrm{ALG} / \mathrm{K}_{3} \mathrm{PA}\right)_{2} / \mathrm{ALG}, \mathrm{e}\right) \mathrm{Au} / \mathrm{PEI} /\left(\mathrm{ALG} / \mathrm{K}_{3} \mathrm{PA}\right)_{5}$, and f) $\mathrm{Au} / \mathrm{PEI} /\left(\mathrm{ALG} / \mathrm{K}_{3} \mathrm{PA}\right)_{5} / \mathrm{ALG}$. The scale bar is $50 \mu \mathrm{m}$ in all images.

$\mathrm{Au} / \mathrm{PEI} /\left(\mathrm{ALG} / \mathrm{K}_{3} \mathrm{PA}\right)_{2}$ and $\mathrm{Au} / \mathrm{PEI} /\left(\mathrm{ALG} / \mathrm{K}_{3} \mathrm{PA}\right)_{5}$ surfaces, with the fusion index being slightly higher for the one with less number of bilayers. Hence, the effect of the upper layer seems to lose significance while increasing the number of layers, as already discussed above. Moreover, the number of myotubes per area $\left(A=1.55 \times 10^{5} \mu \mathrm{m}^{2}\right)$ was determined for each condition (Figure S11b, Supporting Information). Although not so evident as for the fusion index, these results show that the sample conditions ending in $\mathrm{K}_{3} \mathrm{PA}$ presented higher number of myotubes for the same area. Additionally, the average myotube area (Figure S11c, Supporting Information) and length (Figure S11d, Supporting Information) were examined for each condition. No significant differences were observed between the different sample conditions in terms of myotubes area and length, revealing that in this study topography had more influence on fusion index and myotubes number. Overall, the myogenic differentiation of $\mathrm{C} 2 \mathrm{C} 12$ cells seeded on $\mathrm{Au} / \mathrm{PEI} /(\mathrm{ALG} /$ $\left.\mathrm{K}_{3} \mathrm{PA}\right)_{2}$ surfaces is greater than for the other conditions. Such behavior agrees with previous reports in the literature which demonstrate that enhanced cell adhesion and proliferation can accelerate the myogenic differentiation. ${ }^{[45]}$ As discussed above, although $\mathrm{K}_{3}$ PA does not present bioactive domains in its structure, it confers important properties to the film. The surface topography has been largely studied as a determinant factor to modulate cell differentiation and, concretely, fiberlike topographies have been reported as adjuvant for myogenic differentiation. ${ }^{[46]}$

\section{Conclusion}

In summary, we have successfully designed and developed for the first time stable biomimetic biopolymer/peptide amphiphile hybrid supramolecular multilayered biomaterials by combining the self-assembly strategy with the electrostatic-driven LbL assembly technology, as well as exploiting the synergistic interaction and dynamic nature of both building blocks. The dynamic nature of the assembly process is mainly driven by the attractive electrostatic interactions between the large negatively charged ALG macromolecule and oppositely charged self-assembling small $\mathrm{K}_{3}$ PA molecule that leads to the formation of nanofiber bundles, as well as by the intrinsic dynamic peptide molecular structure. However, other highly dynamic and reversible noncovalent forces, including hydrogen bonding and hydrophobic forces, may also play a role on the synergistic assembly of the dynamic $\mathrm{ALG} / \mathrm{K}_{3} \mathrm{PA}$ supramolecular system. The sequential deposition of negatively charged high-molecularweight ALG biopolymer and oppositely charged self-assembling low-molecular-weight $\mathrm{K}_{3}$ PA was monitored in situ by QCM-D which revealed the nanostructured dimension and linear growth regime exhibited by the supramolecular multilayered assemblies. The morphological and structural properties were further examined by AFM, SEM, and TEM, showing the nanofibrillar structure of the developed films, thus mimicking the structural and functional features of the native cellular environment. The in vitro biological performance of the new developed supramolecular multilayered nanostructures was assessed using $\mathrm{C} 2 \mathrm{C} 12$ myoblast cells, in an attempt to investigate their biocompatibility. The supramolecular multilayered nanostructures ending in $\mathrm{K}_{3} \mathrm{PA}$ showed enhanced cell adhesion and activity in comparison with similar films ending with ALG, thus positively influencing the cell behavior. Furthermore, the myogenic differentiation studies demonstrated that hybrid ALG/ $\mathrm{K}_{3}$ PA supramolecular multilayered nanofilms led $\mathrm{C} 2 \mathrm{C} 12$ cells to differentiate into multinucleated myotubes revealing a tube-like morphology, thus proving their myogenic potential. This potential seemed to be boosted when cells were cultured above $\mathrm{K}_{3}$ PA-ending nanofilms. Interestingly, such PA does not contain any bioactive epitopes, i.e., cell-adhesive motifs, in its structure that could boost and support the superior cell attachment, thus reinforcing their great potential as bioinstructive matrices for biomedical applications, including cell culture. 
Although, several studies will be critical to infer on the translatability of these supramolecular nanofiber structures, we envision that the strategy herein presented could be transposed into more complex devices incorporating various biologically active building blocks and functionalities, including freestanding membranes, micro- and nanocapsules, and 3D constructs. Such devices would have great potential to be applied as supramolecular biomaterials for several biomedical and healthcare applications, including as cell culture platforms, controlled drug delivery systems, or as bioinstructive structures to support myoblast cell growth for muscle tissue regeneration. Moreover, the possibility of combining biopolymers and self-assembling peptide amphiphile molecules into nanostructured multilayered films could also open new horizons and perspectives in the design and development of advanced nanostructured functional materials for nonmedical applications, including energy, catalysis, photonics, electronics, or optics.

\section{Experimental Section}

Materials: All protected amino acids, $\left[4-\left[\alpha-\left(2^{\prime}, 4^{\prime}\right.\right.\right.$-dimethoxyphenyl) Fmoc-aminomethyl]phenoxy]acetamidonorleucyl-methylbenzhydrylamine (methylbenzhydrylamine, MBHA) resin (Fmoc-Rink amide MBHA resin), and 2-(1H-benzotriazol-1-yl)-1,1,3,3-tetramethyluronium hexafluorophosphate (HBTU) were purchased from NovaBiochem. Other chemicals, including dichloromethane (DCM), dimethylformamide (DMF), acetonitrile, piperidine, acetic anhydride, $\mathrm{N}, \mathrm{N}$-diisopropylethylamine, and trifluoroacetic acid (TFA), were purchased from Fisher, Merck, Alfa Aesar, or Sigma-Aldrich. CHT of medium molecular weight $\left(M_{\mathrm{w}}\right.$ $=190-310 \mathrm{kDa}, 82 \%$ degree of acetylation, viscosity 200-800 cP) was purchased from Sigma-Aldrich (USA) and purified prior to use by a series of filtration and precipitation steps in water and ethanol, followed by freeze drying, as described ref. [47]. Low viscosity sodium ALC derived from brown algae $\left(M_{\mathrm{w}}=538 \mathrm{kDa}\right.$, viscosity $\left.\approx 250 \mathrm{cP}\right)$ and PEI solution $\left(50 \% \mathrm{w} / \mathrm{v}\right.$ in water, $M_{\mathrm{w}}=750 \mathrm{kDa}$ ) was purchased from SigmaAldrich (USA) and used as received. All other chemicals, including acetic acid (VWR, $100 \%, \mathrm{CH}_{3} \mathrm{COOH}$ ) and sodium acetate trihydrate (SigmaAldrich, $\geq 99 \%, \mathrm{CH}_{3} \mathrm{COONa} \cdot 3 \mathrm{H}_{2} \mathrm{O}$ ) were of analytical grade and used as received. $0.1 \mathrm{M}$ acetate buffer $\mathrm{pH} 5.5$ stock solutions were prepared using ultrapure water from a Milli-Q Plus water purification system (resistivity $>18.2 \mathrm{M} \Omega \mathrm{cm}$ ) from Millipore.

Substrates Pretreatment: Gold-coated $5 \mathrm{MHz}$ AT-cut quartz crystal substrates (QSX301 Gold, Q-Sense, Sweden) were submitted to UV/ ozone (UV/Ozone ProCleaner 220, BioForce Nanosciences, Inc.) treatment for $10 \mathrm{~min}$, followed by immersion in an RCA cleaning solution (5:1:1 ultrapure water:ammonia (25\%):hydrogen peroxide $(30 \%), v / v)$ in an ultrasound bath at $70{ }^{\circ} \mathrm{C}$ for $20 \mathrm{~min}$. Subsequently, the quartz crystal substrates were thoroughly rinsed with ultrapure water and ethanol, dried under a soft stream of $\mathrm{N}_{2}$, and resubmitted to UV/ozone treatment for $10 \mathrm{~min}$. Then, the freshly cleaned quartz crystal substrates were immediately inserted in the QCM-D chamber for the buildup of the multilayered coatings. The same cleaning procedure was applied to the gold-coated glass substrates (IK4-Tekniker, thickness of Au layer: $50 \mathrm{~nm}$; $1 \times 1 \mathrm{~cm}^{2}$ ) used for the fabrication of the nanostructured multilayered thin films for microscopy analysis, water contact angle measurements, and in vitro cell culture studies.

Synthesis and Purification of PA: $\mathrm{K}_{3} \mathrm{PA}$ (Lauryl-Val-Val-Ala-Gly-Lys-LysLys-Am, $\left.M_{\mathrm{w}}=910.67 \mathrm{Da}\right)$ molecule was synthesized via Fmoc-solidphase peptide synthesis method. ${ }^{[48]}$ During the synthesis, rink amide $\mathrm{MBHA}$ resins were used as solid supports. The carboxylate group of 2 mol equivalents of amino acid was activated by 1.95 mol equivalents of HBTU and 3 mol equivalents of $N, N$-diisopropylethylamine (DIEA) on the $1 \mathrm{~mol}$ equivalent of the solid support. Fmoc protecting groups were removed at each coupling step with $20 \%(\mathrm{v} / \mathrm{v})$ piperidine/DMF solution for $25 \mathrm{~min}$. The amino acid coupling time was set to be $2 \mathrm{~h}$ at each cycle. Lauric acid, which served as the source of lauryl group, was reacted with the amine group and its coupling mechanism was similar to the amino acid coupling. A $10 \%(\mathrm{v} / \mathrm{v})$ acetic anhydride/DMF mixture was used to acetylate the unreacted amine groups after each coupling step. The cleavage solution prepared as the mixture of $95 \%$ TFA, $2.5 \%$ water, and $2.5 \%$ triisopropylsilane was used to cleave the side chain protecting groups and remove the PA molecules form the solid support for $3 \mathrm{~h}$. After the cleavage step, the resins were washed with DCM to obtain the synthesized PA molecules in the solution phase. The excess of organic solvents and TFA was removed using a rotary evaporation system. Then, cold diethyl ether at $-20{ }^{\circ} \mathrm{C}$ was added onto the synthesized PAs for promoting the precipitation and sedimentation overnight. The white precipitate was collected by centrifugation at $4{ }^{\circ} \mathrm{C}$, dissolved in distilled water, and the solution was frozen at $-80{ }^{\circ} \mathrm{C}$. Afterward, the frozen sample was freeze dried for $3 \mathrm{~d}$ to obtain the PA powder.

LC-MS: The purity of the PA was assessed using an Agilent 6530 Accurate-Mass Quadrupole time-of-flight mass spectrometry (LC-MS) apparatus with electrospray ionization source connected to reversephase analytical high performance liquid chromatography (HPLC) system. A total of $1 \mathrm{mg} \mathrm{mL}^{-1} \mathrm{~K}_{3} \mathrm{PA}$ molecule was dissolved in water and analyzed via LC-MS using an Agilent Zorbax Extend-C18 column $(3.5 \mu \mathrm{m} 80 \mathrm{~A}, 100 \times 4.6 \mathrm{~mm})$ in an optimized gradient of water $(0.1 \%$ formic acid) and acetonitrile ( $0.1 \%$ formic acid). The synthesized peptide was purified with an Agilent 1200 Series preparative HPLC System.

$C D$ Spectroscopy: Before the analysis of the secondary structure of the synthesized PA molecule ( $\left.\mathrm{K}_{3} \mathrm{PA}\right)$, the ALG biopolymer, and the $A L G / K_{3} P A$ system by $C D$ spectroscopy, $0.3 \mathrm{mg} \mathrm{mL}^{-1} \mathrm{~K}_{3} \mathrm{PA}, 0.1 \mathrm{mg} \mathrm{mL}^{-1} \mathrm{ALG}$, and ALC $/ K_{3} P A(1: 1, v / v)$ mixture solutions were freshly prepared in $0.01 \mathrm{M}$ acetate buffer at $\mathrm{pH}$ 5.5. A lower ionic strength was used to decrease the voltage during the measurements and avoid the background noise that would have interfered with the measurement. The CD spectra were recorded at room temperature $\left(25^{\circ} \mathrm{C}\right)$ in a JASCO J-815 circular dichroism spectrometer from 190 to $300 \mathrm{~nm}$ at a scanning speed of $100 \mathrm{~nm} \mathrm{~min} \mathrm{~m}^{-1}$, using a digital integration time of $4 \mathrm{~s}$, a bandwidth of $1 \mathrm{~nm}$, and with a data pitch of $0.1 \mathrm{~nm}$ and standard sensitivity.

ATR-FTIR Spectroscopy: A Bruker TENSOR 27 FTIR spectrometer fitted with a "Golden Gate" ATR module equipped with a diamond crystal was used to collect the spectra of the dried ALG, $\mathrm{K}_{3} \mathrm{PA}$, and ALG $/ \mathrm{K}_{3} \mathrm{PA}$ $(1: 1, v / v)$ films in the absorbance mode. All data were obtained in the spectral range of $4000-400 \mathrm{~cm}^{-1}$ by averaging 256 individual scans per sample at a resolution of $4 \mathrm{~cm}^{-1}$. Collected spectra were linear baseline corrected, normalized, and subsequently deconvoluted by fitting with a Gaussian function using the "Fourier Self-Deconvolution" tab enclosed in the OPUS spectroscopy software supplied with the instrument.

Zeta (५)-Potential Measurements: In order to assess the fabrication of $\mathrm{ALG} / \mathrm{K}_{3} \mathrm{PA}$ system, the electrical charge of the ALG and $\mathrm{K}_{3} \mathrm{PA}$ molecules at the working $\mathrm{pH}$ of 5.5 was investigated by measuring their zeta

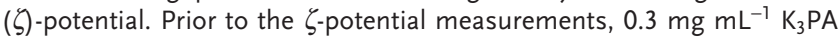
and $0.1 \mathrm{mg} \mathrm{mL}^{-1}$ ALG solutions were freshly prepared in $0.1 \mathrm{M}$ acetate buffer at $\mathrm{pH}$ 5.5. The $\zeta$-potentials of both individual solutions were determined at $25{ }^{\circ} \mathrm{C}$ using a Zetasizer Nano-ZS (Malvern Instruments Ltd., UK). The measurements were performed in triplicate and averaged for each sample.

QCM-D: The buildup of the supramolecular multilayered assemblies comprising peptide amphiphile and polysaccharides onto the goldcoated $5 \mathrm{MHz}$ AT-cut quartz crystal sensors (QSX301 Gold, Q-Sense, Sweden) was monitored in situ by quartz crystal microbalance with dissipation monitoring (QCM-D, Q-Sense E4, Sweden) in a liquid environment. The freshly cleaned gold-plated quartz crystals substrates were immediately inserted in the QCM-D chamber, equilibrated in a $0.1 \mathrm{M}$ acetate buffer solution at $\mathrm{pH} 5.5$ until a baseline was reached, and further modified with a positively charged PEI precursor layer to form an anchoring layer on the surface and to compensate for small surface inhomogeneity in the charge density. For this purpose, a $0.5 \mathrm{mg} \mathrm{mL}-1$ PEI solution in $0.1 \mathrm{M}$ acetate buffer at $\mathrm{pH} 5.5$ was pumped into the measuring chamber for $\approx 25 \mathrm{~min}$, following by a $10 \mathrm{~min}$ rinsing step in 
the aforementioned buffer solution to remove unbounded molecules. Afterward, the PEl-functionalized Au-plated quartz crystals were alternately exposed to $0.1 \mathrm{mg} \mathrm{mL}^{-1}$ ALG ( $15 \mathrm{~min}$ adsorption time) and $0.3 \mathrm{mg} \mathrm{mL}^{-1} \mathrm{~K}_{3} \mathrm{PA}(30 \mathrm{~min}$ adsorption time) solutions in $0.1 \mathrm{M}$ acetate buffer at $\mathrm{pH} 5.5$, rendering the surface negatively and positively charged respectively, to buildup the $\mathrm{PEI} /\left(\mathrm{ALG} / \mathrm{K}_{3} \mathrm{PA}\right)_{5}$ multilayered films. A long adsorption time was chosen for the deposition of the $\mathrm{K}_{3} \mathrm{PA}$ layer in order to allow it to reach equilibrium. After each deposition step, the substrates were rinsed with the aforementioned buffer solution for $10 \mathrm{~min}$ to remove weakly adsorbed molecules. The assembly process was repeated until reaching a $\left(\mathrm{ALG} / \mathrm{K}_{3} \mathrm{PA}\right)_{n}$ multilayered film with the desired number of layers $(n)$. The final multilayered thin films were dried under a soft stream of $\mathrm{N}_{2}$. The same procedure was followed for the buildup of the $\left(\mathrm{CHT} / \mathrm{K}_{3} \mathrm{PA}\right)_{3} /\left(\mathrm{ALG} / \mathrm{K}_{3} \mathrm{PA}\right)_{3}$ multilayered thin films as control sample on the gold-plated quartz crystal substrates. All the experiments were performed at $25{ }^{\circ} \mathrm{C}$ and at a constant flow rate of $50 \mu \mathrm{L} \mathrm{min}{ }^{-1}$. The gold-coated quartz crystal substrates were excited at multiple overtones $(1,3,5,7,9,11$, and 13 corresponding to $5,15,25$, $35,45,55$, and $65 \mathrm{MHz}$, respectively) and variations in frequency $(\Delta f)$ and in dissipation $(\Delta D)$ were monitored in real time. The frequency of each overtone was normalized to the fundamental resonant frequency of the quartz crystal substrate $\left(\Delta f_{n} / n\right.$, in which $n$ denotes the overtone number). The results herein presented correspond to the frequency and energy dissipation shifts associated to the 7th overtone $(35 \mathrm{MHz})$, as they presented the lowest level of noise. Nevertheless, the results were representative of the other overtones. The thickness of the multilayered thin films at each deposition cycle was estimated using the Voigt-based viscoelastic model implemented in the Q-Tools software from Q-Sense, assuming a fluid density of $1020 \mathrm{~kg} \mathrm{~m}^{-3}$, a layer density of $1200 \mathrm{~kg} \mathrm{~m}^{-3}$, and a fluid viscosity of $1 \mathrm{mPa}$.

The nanostructured multilayered thin films were similarly deposited on freshly cleaned Au-coated glass substrates (IK4-Tekniker, Au layer: $50 \mathrm{~nm} ; 1 \times 1 \mathrm{~cm}^{2}$ ) as for the microscopy analysis, water contact angle measurements, and in vitro cell culture studies. Briefly, the Au-coated substrates were first immersed in PEI solution $\left(0.5 \mathrm{mg} \mathrm{mL}^{-1}\right.$ in acetate buffer at $\mathrm{pH} 5.5 ; 25 \mathrm{~min})$, following by the sequential and repetitive immersion in ALG $\left(0.1 \mathrm{mg} \mathrm{mL}^{-1}\right.$ in acetate buffer at $\left.\mathrm{pH} 5.5 ; 15 \mathrm{~min}\right)$ and $\mathrm{K}_{3} \mathrm{PA}\left(0.3 \mathrm{mg} \mathrm{mL}^{-1}\right.$ in acetate buffer at $\left.\mathrm{pH} 5.5 ; 30 \mathrm{~min}\right)$ solutions to build $\left(\mathrm{ALG} / \mathrm{K}_{3} \mathrm{PA}\right)_{n}$ bilayers over the PEI-functionalized Au substrate. Between the adsorption of each layer, a $10 \mathrm{~min}$ rinsing step in $0.1 \mathrm{M}$ acetate buffer solution at $\mathrm{pH} 5.5$ was applied to remove weakly adsorbed molecules.

WCA Measurements: The wettability of the individual materials as well as multilayered films-functionalized Au-coated substrates was determined in air at room temperature through the static sessile drop method using a contact angle goniometer (OCA 15+, DataPhysics Instruments, Germany). The WCA measurements were carried out at room temperature by creating ultrapure water drops of $5 \mu \mathrm{L}$ at the tip of the syringe, followed by placing them over the modified Au-plated substrates. The SCA20 software was used for the analysis of surfacedrop contact angles at each surface. The measurements were repeated three times per sample and averaged for each nanofilm formulation.

TEM: TEM analysis was performed on a Hitachi $\mathrm{H}-9000$ instrument at an acceleration voltage of $300 \mathrm{kV}$. Prior to the TEM analysis, $0.3 \mathrm{mg} \mathrm{mL}^{-1}$ $\mathrm{K}_{3} \mathrm{PA}$ and $0.1 \mathrm{mg} \mathrm{mL}^{-1} \mathrm{ALG}$ solutions were prepared separately in $0.1 \mathrm{M}$ acetate buffer at $\mathrm{pH} 5.5$. In addition, $0.1 \mathrm{mg} \mathrm{mL}^{-1} \mathrm{ALG}$ and $0.3 \mathrm{mg} \mathrm{mL}^{-1}$ $\mathrm{K}_{3} \mathrm{PA}$ solutions were mixed at a $1: 1$ ratio $(\mathrm{v} / \mathrm{v})$ in $0.1 \mathrm{M}$ acetate buffer at $\mathrm{pH}$ 5.5. After the preparation of the individual solutions and $\mathrm{ALG} / \mathrm{K}_{3} \mathrm{PA}$ mixture, $5 \mu \mathrm{L}$ of each sample solution was drop casted onto carbon filmcoated copper TEM grids (CF400-Cu-carbon film 400 square mesh copper grid) and incubated for $15 \mathrm{~min}$. Then, the excess of sample was removed from the surface of the grid by micropipette. Afterward, a $5 \mu \mathrm{L}$ drop of $0.5 \mathrm{wt} \%$ uranyl acetate solution (freshly prepared, sonicated, and filtered) was put over the TEM grids consisting of the samples. After the staining, the grids were air dried in the fume hood under ambient conditions overnight.

AFM: AFM measurements were performed in air at room temperature $\left(25^{\circ} \mathrm{C}\right)$ using a Dimension Icon Atomic Force Microscope (Bruker, France) operated in the ScanAsyst mode. Silicon nitride cantilevers (ScanAsyst-Air, Bruker, France) with a resonance frequency of $70 \mathrm{kHz}$ and a nominal spring constant of $0.4 \mathrm{~N} \mathrm{~m}^{-1}$ were used for imaging. The surface topography of the dried samples (individual ALC and $\mathrm{K}_{3} \mathrm{PA}$ samples, $\mathrm{ALG} / \mathrm{K}_{3} \mathrm{PA}$ mixture $\left(1: 1, \mathrm{v} / \mathrm{v}\right.$ ratio), and $\left(\mathrm{ALG} / \mathrm{K}_{3} \mathrm{PA}\right)_{n}$ multilayered assemblies) was scanned over $5 \times 5$ and $2 \times 2 \mu \mathrm{m}^{2}$ regions at a fixed scan rate of $1 \mathrm{~Hz}$ with a resolution of $512 \times 512$ pixels. For the AFM analysis, $10 \mu \mathrm{L}$ of each individual ALG and $\mathrm{K}_{3} \mathrm{PA}$ solutions as well as ALG $/ K_{3} P A$ mixture were separately deposited onto freshly cleaned glass coverslips and allowed to dry in air at room temperature. The substrates were then gently rinsed with ultrapure water and air dried at room temperature. In the case of the $\left(\mathrm{ALG} / \mathrm{K}_{3} \mathrm{PA}\right)_{n}$ multilayered assemblies, after the fabrication of the coatings onto the freshly cleaned gold-coated glass substrates, the substrates were also gently rinsed in ultrapure water and air dried prior to AFM imaging. At least three different samples and five different areas from each sample formulation were randomly scanned and representative images were chosen for analysis. Raw AFM data were processed by flattening and plane fitting and further analyzed using the NanoScope Analysis 1.50 software (Bruker, France). Statistical parameters, including the RMS surface roughness, were derived from the AFM topographical images by software analysis.

SEM: SEM imaging was performed on an ultrahigh-resolution field emission gun scanning electron microscope (FEI Nova NanoSEM 200 Eindhoven, the Netherlands) operated in the secondary electrons mode at accelerating voltages of 5 and $10 \mathrm{kV}$ and working distances between 5.0 and $5.5 \mathrm{~mm}$. Prior to the analysis, the gold-coated glass substrates containing the adsorbed layers were fixed to the aluminum stubs by double-sided carbon conductive adhesive tape for electrical contact purposes.

In Vitro Cell Culture Studies: A mouse model of muscle cells, the C2C12 cell line (ATCC CRL-1772TM), was cultured using $150 \mathrm{~cm}^{2}$ cell culture flasks containing low glucose DMEM (Sigma-Aldrich, USA) supplemented with $10 \%$ fetal bovine serum (Biochrom AG, Germany) and $1 \%$ penicillin/streptomycin (Sigma-Aldrich), in a humidified incubator at $37^{\circ} \mathrm{C}$ and $5 \% \mathrm{CO}_{2}$. To preserve the myoblast characteristics, the passage of the cells was performed at cell confluency between 50 and $60 \%$. Prior to cell culture, the Au-coated glass substrates were exposed to UV light irradiation during $30 \mathrm{~min}$ using an UV/Ozone cleaner equipment (ProCleaner 220, BioForce Nanosciences, Inc.), in order to sterilize the samples.

The $\mathrm{C} 2 \mathrm{C} 12$ cell viability on $\mathrm{K}_{3} \mathrm{PA}$ - and ALG-ending multilayered coatings-(ALG/K $\left./ K_{3} P A\right)_{n}$ and $\left(A L G / K_{3} P A\right)_{n} / A L G$ films, respectivelywas assessed at different time points using the MTS assay (Cell Titer 96 Aqueous One, Promega, USA). $\mathrm{C} 2 \mathrm{C} 12$ were seeded at a density of $1.5 \times 10^{4}$ cells per sample, dropping a cell suspension of $200 \mu \mathrm{L}$ directly above the sample. After $4 \mathrm{~h}$, the cells were nourished with serum-free growth medium. After 1,3 , and $5 \mathrm{~d}$ of standard incubation the $\mathrm{C} 2 \mathrm{C} 12$ seeded samples were washed twice with sterile phosphate buffered saline (PBS, Sigma-Aldrich) and immersed in $500 \mu \mathrm{L}$ of 4:1 serumfree DMEM/MTS solution. After $3 \mathrm{~h}$ of incubation at $37{ }^{\circ} \mathrm{C}$ and $5 \%$ of $\mathrm{CO}_{2}$, the medium of each sample was collected and added to a 96-well plate in triplicate; the metabolic activity was quantified by measuring the absorbance at $490 \mathrm{~nm}$, using a microplate reader. Experiments were carried out with $n=3$ and the results were normalized to TCPS surface area (3D Biomatrix, USA).

Cell morphology studies were also assessed. The same cell density was used and the culture was maintained under serum-free growth medium during 1,3 , and $5 \mathrm{~d}$. After these time points, the cells were fixed with 10\% formalin (Sigma-Aldrich)/PBS during $30 \mathrm{~min}$, permeabilized on $0.2 \%$ Triton X-100 (Sigma-Aldrich) for $5 \mathrm{~min}$, and blocked with 3\% $(\mathrm{w} / \mathrm{v})$ bovine serum albumin (BSA, Sigma-Aldrich)/PBS for $30 \mathrm{~min}$ Then, the cells were stained by immersing the samples first with a solution of 1:200 phalloidin (Sigma-Aldrich) in PBS during $45 \mathrm{~min}$ and then with a solution of 1:1000 4',6-diamidine-2'-phenylindole dihydrochloride (DAPI, Sigma-Aldrich) in PBS during $15 \mathrm{~min}$. Between each step the samples were washed several times with PBS. In the end of the process, the samples were imaged at $10 \times$ and $20 \times$ magnifications using a Transmitted and Reflected Light Microscope with ApoTome 2 (Axio Imager Z1m, Zeiss, Germany). 
For the differentiation studies, the $\mathrm{C} 2 \mathrm{C} 12$ cells were cultured on $\mathrm{K}_{3} \mathrm{PA}$ and ALG-ending multilayered coatings- $\left(\mathrm{ALG} / \mathrm{K}_{3} \mathrm{PA}\right)_{n}$ and $\left(\mathrm{ALG} / \mathrm{K}_{3} \mathrm{PA}\right)_{n} /$ ALC films, respectively-at a cell density of $1.0 \times 10^{4}$ cells per sample. When cells achieved $70-80 \%$ confluence, the serum-free growth medium was replaced with low-glucose DMEM supplemented with $2 \%$ horse serum (HS, Invitrogen), 1\% penicillin/streptomycin, in order to induce cell differentiation. To evaluate the differentiation abilities of these cells cultured above nanofibers-coated surfaces, immunocytochemistry assays were performed. For this, an antibody against troponin $\mathrm{T}$ was used as a marker of myogenic differentiation. After $5 \mathrm{~d}$, the cells were fixed with $10 \%$ formalin/PBS and then permeabilized with $0.1 \%$ triton-100x. The samples were then blocked with $0.3 \%(\mathrm{w} / \mathrm{v}) \mathrm{BSA}$ in PBS and incubated with 1:100 primary antibody troponin-T (Acris Antibodies, Inc, Germany) in PBS overnight at $4{ }^{\circ} \mathrm{C}$. In the day after, the samples were incubated with 1:1000 secondary antibody antimouse Alexa Fluor 488 (Invitrogen) in $1 \% \mathrm{HS}$ in PBS, during $1 \mathrm{~h}$ at room temperature and in the dark. Between each step, several washes with PBS were performed. In the end of this process, the samples were maintained in PBS overnight and imaged with fluorescence microscope in the day after. Negative controls were achieved by excluding the incubation with the primary antibody and instead incubated with $1 \%$ HS in PBS

Quantitative analysis of the myogenic $\mathrm{C} 2 \mathrm{C} 12$ differentiation was performed by calculating the fusion index, the troponin T-positive myotubes area, number, and the myotubes length. The fusion index corresponds to the percentage of the number of nuclei within the multinucleated myotubes to the total number of nuclei. Four images of each condition were analyzed using an image processing software (Image), National Institutes of Health, Bethesda, MD, USA).

All experiments were conducted at $37{ }^{\circ} \mathrm{C}$ and $5 \% \mathrm{CO}_{2}$, using cells at passage between 6 and 8 and with medium being exchanged every $2 \mathrm{~d}$.

Statistical Analysis: Unless otherwise noted, all experiments were performed in triplicate $(n=3)$ and the results were presented as mean \pm standard deviation. Statistical analysis was performed with the GraphPad 6.0 software, using the one-way analysis of variance test with Bonferroni post hoc multiple comparison test; differences were considered statistically significant for a $p<0.05$.

\section{Supporting Information}

Supporting Information is available from the Wiley Online Library or from the author.

\section{Acknowledgements}

The authors acknowledge the financial support by the Portuguese Foundation for Science and Technology (FCT) through the Postdoctoral (SFRH/BPD/103604/2014—João Borges; SFRH/BPD/96797/2013Sofia G. Caridade) and PhD (SFRH/BD/97606/2013-Maria P. Sousa) grants. This work was also supported by the European Research Council Grant Agreement ERC-2014-ADG-669858 for project "ATLAS", as well as by the H2020-TWINN-2015 - Twinning European project "CHEM2NATURE" (Grant Agreement no. 692333). The Acknowledgements were modified to include cover funding on May 4, 2017 , following initial online publication.

Received: October 1, 2016

Revised: November 11, 2016

Published online: February 15, 2017

[1] C. J. Pedersen, J. Am. Chem. Soc. 1967, 89, 7017.

[2] D. J. Cram, T. Kaneda, R. C. Helgeson, S. B. Brown, C. B. Knobles, E. Maverick, K. N. Trueblood, J. Am. Chem. Soc. 1985, 107, 3645.
[3] J.-M. Lehn, Science 2002, 295, 2400.

[4] a) S. I. Stupp, V. LeBonheur, K. Walker, L. S. Li, K. E. Huggins, M. Keser, A. Amstutz, Science 1997, 276, 384; b) B. Rybtchinski, ACS Nano 2011, 5, 6791; c) T. Aida, E. W. Meijer, S. I. Stupp, Science 2012, 335, 813; d) E. A. Appel, J. del Barrio, X. J. Loh, O. A. Scherman, Chem. Soc. Rev. 2012, 41, 6195; e) K. Liu, Y. T. Kang, Z. Q. Wang, X. Zhang, Adv. Mater. 2013, 25, 5530; f) E. Busseron, Y. Ruff, E. Moulin, N. Giuseppone, Nanoscale 2013, 5, 7098; g) S. I. Stupp, L. C. Palmer, Chem. Mater. 2014, 26, 507; h) J. Boekhoven, S. I. Stupp, Adv. Mater. 2014, 26, 1642; i) R. Freeman, J. Boekhoven, M. B. Dickerson, R. R. Naik, S. I. Stupp, MRS Bull. 2015, 40, 1089; j) X. Ma, Y. Zhao, Chem. Rev. 2015, 115, 7794; k) M. J. Webber, E. A. Appel, E. W. Meijer, R. Langer, Nat. Mater. 2016, 15, 13.

[5] a) G. M. Whitesides, B. Grzybowski, Science 2002, 295, 2418; b) S. G. Zhang, Nat. Biotechnol. 2003, 21, 1171; c) A. C. Mendes, E. T. Baran, R. L. Reis, H. S. Azevedo, Wiley Interdiscip. Rev.: Nanomed. Nanobiotechnol. 2013, 5, 582; d) C. Heinzmann, C. Weder, L. M. de Espinosa, Chem. Rev. 2015, 115, 7794; e) Y. Tu, F. Peng, A. Adawy, Y. Men, L. K. E. A. Abdelmohsen, D. A. Wilson, Chem. Rev. 2016, 116, 2023.

[6] a) R. Langer, D. A. Tirrell, Nature 2004, 428, 487; b) J. F. Mano, Mater. Lett. 2015, 141, 198; c) M. Zhao, G. Altankov, U. Grabiec, M. Bennett, M. Salmeron-Sanchez, F. Dehghani, T. Groth, Acta Biomater. 2016, 41, 86.

[7] a) J. D. Hartgerink, E. Beniash, S. I. Stupp, Proc. Natl. Acad. Sci. USA 2002, 99, 5133; b) S. Toksöz, M. O. Guler, Nano Today 2009, 4, 458; c) H. Cui, M. J. Webber, S. I. Stupp, Biopolymers 2010, 94, 1; d) R. Mammadov, B. Mammadov, S. Toksoz, B. Aydin, R. Yagci, A. B. Tekinay, M. O. Guler, Biomacromolecules 2011, 12, 3508; e) S. I. Stupp, R. H. Zha, L. C. Palmer, H. Cui, R. Bitton, Faraday Discuss. 2013, 166, 9; f) E. Arslan, I. C. Garip, G. Gulseren, A. B. Tekinay, M. O. Guler, Adv. Healthcare Mater. 2014, 3, 1357.

[8] a) R. M. Capito, H. S. Azevedo, Y. S. Velichko, A. Mata, S. I. Stupp, Science 2008, 319, 1812; b) Y. S. Velichko, J. R. Mantei, R. Bitton, D. Carvajal, K. R. Shull, S. I. Stupp, Adv. Funct. Mater. 2012, 22, 369; c) R. Bitton, L. W. Chow, R. H. Zha, Y. S. Velichko, E. T. Pashuck, S. I. Stupp, Small 2014, 10, 500; d) K. E. Inostroza-Brito, E. Collin, O. Siton-Mendelson, K. H. Smith, A. Monge-Marcet, D. S. Ferreira, R. P. Rodríguez, M. Alonso, J. C. Rodríguez-Cabello, R. L. Reis, F. Sagués, L. Botto, R. Bitton, H. S. Azevedo, A. Mata, Nat. Chem. 2015, 7, 897.

[9] a) L. W. Chow, R. Bitton, M. J. Webber, D. Carvajal, K. R. Shull, A. K. Sharma, S. I. Stupp, Biomaterials 2011, 32, 1574; b) R. H. Zha, S. Sur, S. I. Stupp, Adv. Healthcare Mater. 2013, 2, 126.

[10] a) D. S. Ferreira, R. L. Reis, H. S. Azevedo, Soft Matter 2013, 9, 9237; b) D. I. Rozkiewicz, B. D. Myers, S. I. Stupp, Angew. Chem. Int. Ed. 2011, 50, 6324.

[11] a) J. D. Hartgerink, E. Beniash, S. I. Stupp, Science 2001, 294, 1684; b) H. Ceylan, A. B. Tekinay, M. O. Guler, Biomaterials 2011, 32, 8797; c) G. Gulseren, I. C. Yasa, O. Ustahuseyin, E. D. Tekin, A. B. Tekinay, M. O. Guler, Biomacromolecules 2015, 16, 2198.

[12] G. Decher, Science 1997, 277, 1232

[13] J. Borges, J. F. Mano, Chem. Rev. 2014, 114, 8883.

[14] a) A. I. Neto, A. C. Cibrão, C. R. Correia, R. R. Carvalho, G. M. Luz, G. G. Ferrer, G. Botelho, C. Picart, N. M. Alves, J. F. Mano, Small 2014, 10, 2459; b) J. Borges, S. G. Caridade, J. M. Silva, J. F. Mano, Macromol. Rapid Commun. 2015, 36, 405.

[15] a) J. M. Silva, A. R. C. Duarte, C. A. Custódio, P. Sher, A. I. Neto, A. C. M. Pinho, J. Fonseca, R. L. Reis, J. F. Mano, Adv. Healthcare Mater. 2014, 3, 433; b) P. Sher, C. A. Custódio, J. F. Mano, Small 2010, 6, 2644; c) C. R. Correia, R. L. Reis, J. F. Mano, Biomacromolecules 2013, 14, 743

[16] a) J. Borges, L. C. Rodrigues, R. L. Reis, J. F. Mano, Adv. Funct. Mater. 2014, 24, 5624; b) R. R. Costa, J. F. Mano, Chem. Soc. Rev. 2014, 43, 3453. 
[17] J. Hiller, J. D. Mendelsohn, M. R. Rubner, Nat. Mater. 2002, 1, 59.

[18] D. M. DeLongchamp, M. Kastantin, P. T. Hammond, Chem. Mater. 2003, 15, 1575

[19] Y. Xiang, S. Lu, S. P. Jiang, Chem. Soc. Rev. 2012, 41, 7291.

[20] N. J. Greenfield, Trends Anal. Chem. 1999, 18, 236.

[21] A. Micsonai, F. Wien, L. Kernya, Y.-H. Lee, Y. Goto, M. Réfrégiers, J. Kardos, Proc. Natl. Acad. Sci. USA 2015, 112, E3095.

[22] C. Sartori, D. S. Finch, B. Ralph, K. Gilding, Polymer 1997, 38, 43.

[23] D. M. Byler, H. Susi, Biopolymers 1986, 25, 469.

[24] a) S. Krimm, J. Bandekar, Adv. Protein Chem. 1986, 38, 181; b) W. K. Surewicz, H. H. Mantsch, D. Chapman, Biochemistry 1993 32, 389; c) N. Demirdöven, C. M. Cheatum, H. S. Chung, M. Khalil, J. Knoester, A. Tokmakoff, J. Am. Chem. Soc. 2004, 126, 7981.

[25] K. A. Marx, Biomacromolecules 2003, 4, 1099.

[26] F. Höök, B. Kasemo, T. Nylander, C. Fant, K. Sott, H. Elwing, Anal. Chem. 2001, 73, 5796.

[27] C. Picart, P. Lavalle, P. Hubert, F. J. G. Cuisinier, G. Decher, P. Schaaf, J.-C. Voegel, Langmuir 2001, 17, 7414.

[28] M. Rodahl, F. Hook, B. Kasemo, Anal. Chem. 1996, 68, 2219.

[29] S. Toksoz, R. Mammadov, A. B. Tekinay, M. O. Guler, J. Colloid Interface Sci. 2011, 356, 131.

[30] a) F. Kurayama, S. Suzuki, T. Oyamada, T. Furusawa, M. Sato, N. Suzuki, J. Colloid Interface Sci. 2010, 349, 70; b) K. Y. Lee, D. J. Mooney, Prog. Polym. Sci. 2012, 37, 106.

[31] a) D. P. Go, A. Hung, S. L. Gras, A. J. O'Connor, J. Phys. Chem. B 2012, 116, 1120; b) H. F. Chuang, R. C. Smith, P. T. Hammond, Biomacromolecules 2008, 9, 1660; c) O. Etienne, C. Picart, C. Taddei, Y. Haikel, J. L. Dimarcq, P. Schaaf, J.-C. Voegel, J. A. Ogier, C. Egles, Antimicrob. Agents Chemother. 2004, 48, 3662.

[32] a) P. Schultz, D. Vautier, L. Richert, N. Jessel, Y. Haikel, P. Schaaf, I.-C. Voegel, J. Ogier, C. Debry, Biomaterials 2005, 26, 2627; b) F. Fioretti, C. Mendoza-Palomares, M. Helms, D. Al Alam, L. Richert, Y. Arntz, S. Rinckenbach, F. Garnier, Y. Haïkel, S. C. Gangloff, N. Benkirane-Jessel, ACS Nano 2010, 4, 3277.

[33] M. V. Voinova, M. Rodahl, M. Jonson, B. Kasemo, Phys. Scr. 1999, $59,391$.
[34] R. R. Costa, C. A. Custódio, F. J. Arias, J. C. Rodríguez-Cabello, J. F. Mano, Small 2011, 7, 2640.

[35] M. Cantini, M. Sousa, D. Moratal, J. F. Mano, Biomater. Sci. 2013 1, 202.

[36] a) H. J. Kong, M. K. Smith, D. J. Mooney, Biomaterials 2003, 24, 4023; b) B. Sarker, R. Singh, R. Silva, J. A. Roether, J. Kaschta, R. Detsch, D. W. Schubert, I. Cicha, A. R. Boccaccini, PLoS One 2014, 9, e107952; c) A. I. Neto, N. L. Vasconcelos, S. M. Oliveira, D. Ruiz-Molina, J. F. Mano, Adv. Funct. Mater. 2016, 26, 2745.

[37] M. Kushwaha, J. M. Anderson, C. A. Bosworth, A. Andukuri, W. P. Minor, J. R. Lancaster)r., P. G. Anderson, B. C. Brott, H. W. Jun, Biomaterials 2010, 31, 1502.

[38] a) C. H. Kim, M. S. Khil, H. Y. Kim, H. U. Lee, K. Y. Jahng, J. Biomed. Mater. Res., Part B 2006, 78, 283; b) Y. C. Shin, J. H. Lee, M. J. Kim, S. W. Hong, B. Kim, J. K. Hyun, Y. S. Choi, J. C. Park, D. W. Han, J. Biol. Eng. 2015, 9, 22

[39] a) D. M. Copolovici, K. Langel, E. Eriste, Ü. Langel, ACS Nano 2014, 8, 1972; b) D. Mumcuoglu, M. Sardan, T. Tekinay, M. O. Guler, A. B. Tekinay, Mol. Pharmaceutics 2015, 12, 1584.

[40] S. Burattini, P. Ferri, M. Battistelli, R. Curci, F. Luchetti, E. Falcieri, Eur. J. Histochem. 2004, 48, 223.

[41] a) V. Beachley, X. Wen, Prog. Polym. Sci. 2010, 35, 868; b) N. M. Alves, I. Pashkuleva, R. L. Reis, J. F. Mano, Small 2010, 6, 2208.

[42] M. M. Stevens, J. H. George, Science 2005, 310, 1135.

[43] a) Y.-C. Toh, S. Ng, Y. M. Khong, X. Zhang, Y. Zhu, P.-C. Lin, C.-M. Te, W. Sun, H. Yu, Nano Today 2006, 1, 34; b) D.-H. Kim P. P. Provenzano, C. L. Smith, A. Levchenko, J. Cell Biol. 2012, 197, 351.

[44] J. M. Silva, R. L. Reis, J. F. Mano, Small 2016, 12, 4308.

[45] M. Buckingham, Bioessays 2003, 25, 13.

[46] a) S. H. Ku, C. B. Park, Adv. Healthcare Mater. 2013, 2, 1445; b) I. C. Yasa, N. Gunduz, M. Kilinc, M. O. Guler, A. B. Tekinay, Sci. Rep. 2015, 5, 16460.

[47] R. Signini, S. P. Campana-Filho, Polym. Bull. 1999, 42, 159

[48] M. Goktas, G. Cinar, I. Orujalipoor, S. Ide, A. B. Tekinay, M. O. Guler, Biomacromolecules 2015, 16, 1247. 